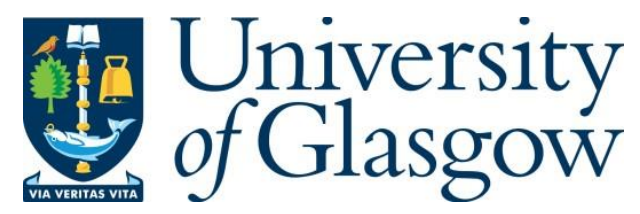

Celis-Morales, C. A. et al. (2019) The combination of physical activity and sedentary behaviors modifies the genetic predisposition to obesity. Obesity, 27(4), pp. 653-661.

There may be differences between this version and the published version. You are advised to consult the publisher's version if you wish to cite from it.

This is the peer reviewed version of the following article: Celis-Morales, C. A. et al. (2019) The combination of physical activity and sedentary behaviors modifies the genetic predisposition to obesity. Obesity, 27(4), pp. 653-661, which has been published in final form at http://dx.doi.org/10.1002/oby.22417

This article may be used for non-commercial purposes in accordance with Wiley Terms and Conditions for Self-Archiving.

http://eprints.gla.ac.uk/173164/

Deposited on: 21 March 2019

Enlighten - Research publications by members of the University of Glasgow http://eprints.gla.ac.uk 


\section{Pharmacodynamic Therapeutic Drug Monitoring for Cancer: Challenges, Advances and Future Opportunities}

Gareth J. Veal, PhD ${ }^{\text {a,* }}$, Edward B. Amankwatia, PhD ${ }^{a}$, Marie-Noëlle Paludetto, PharmD ${ }^{\text {b }}$ Till Möcklinghoff, PharmD a , Fiona Thomson, PhD c, Nicolas André, PhD ${ }^{d}$, Joseph Ciccolini, PhD ${ }^{\text {e }}$ Etienne Chatelut, PhD ${ }^{b}$

${ }^{a}$ Northern Institute for Cancer Research, Newcastle University, Newcastle upon Tyne, NE2 $4 \mathrm{HH}, \mathrm{UK}$

b Institut Claudius-Regaud and Cancer Research Center of Toulouse, Inserm U1037, Université Paul Sabatier, Toulouse, France

c Institute of Cancer Sciences, University of Glasgow, Glasgow, G61 1QH

d Pediatric Hematology and Oncology Unit, La Timone University Hospital of Marseille, Marseille 13005, France

e SMARTc unit, Center for Research on Cancer of Marseille, UMR Inserm 1068, CNRS UMR 7258, Aix Marseille Université, Marseille, France

* Corresponding author: Professor Gareth J. Veal

Northern Institute for Cancer Research

Paul O'Gorman Building

Medical School

Framlington Place

Newcastle University

Newcastle upon Tyne NE2 4HH

UK

Tel: (+44) 01912084332

Fax: (+44) 01912083452

Email: G.J.Veal@ncl.ac.uk

Webpage: http://www.ncl.ac.uk/nicr/staff/profile/garethveal 


\begin{abstract}
In the modern era of cancer treatment, with targeted agents superseding more traditional cytotoxic chemotherapeutics, it is becoming increasingly important to employ stratified medicine approaches to ensure that patients receive the most appropriate drugs and treatment schedules. In this context there is significant potential for the use of pharmacodynamic biomarkers to provide pharmacological information which could be utilised in a therapeutic drug monitoring setting. The current review focuses on discussing some of the challenges faced to date in translating preclinical pharmacodynamic biomarker approaches to a clinical setting, recent advances in important areas including circulating biomarkers and pharmacokinetic/pharmacodynamic modelling approaches and provides some selected examples of anticancer drugs where there is existing evidence for potentially advancing pharmacodynamic therapeutic drug monitoring approaches to deliver more effective treatment. While we may not yet be in a position to systematically implement therapeutic drug monitoring approaches based on pharmacodynamic information in a cancer patient setting, such approaches are likely to become more commonplace in the coming years. Based on ever increasing levels of pharmacodynamic information being generated on newer anti-cancer drugs, facilitated by increasingly advanced and accessible experimental approaches available to researchers to collect these data, we can now look forward optimistically to significant advances being made in this area.
\end{abstract}

Keywords: Cancer, Therapeutic drug monitoring, Pharmacodynamics, Predictive biomarker 


\section{Introduction}

The modern era of targeted drug approaches for the treatment of cancer patients has involved moving away from cytotoxic agents with efficacy against a wide spectrum of tumours, to newer drugs with more focused, target-selective anti-tumour activities. For these targeted agents, treatment is very much being driven by stratified medicine approaches designed to match particular drugs with patients expressing the relevant targets. In this respect there is significant scope for pharmacodynamic biomarkers to provide useful information relating to the pharmacological activity of particular drugs and hence the use of therapeutic drug monitoring is becoming a feasible goal in an oncology clinical setting. While pharmacokinetic therapeutic drug monitoring approaches have been used with some success, for a limited number of traditional cytotoxic and targeted drugs in particular clinical settings, ${ }^{1}$ the use of pharmacodynamic information to guide treatment is to date a relatively underused utility. In addition to supporting decisions made relating to the continuation or cessation of treatment with a particular drug, modelling approaches utilising both pharmacokinetic and pharmacodynamic data provide the opportunity to guide dosing in a more quantitative way. The current review will focus on discussing some of the challenges faced to date in terms of translating preclinical findings to a patient setting, the promises provided by recent advances in research in the area of circulating biomarkers and the importance of pharmacokinetic/pharmacodynamic (PK/PD) modelling approaches. Finally, examples will be provided of agents belonging to cytotoxic drug, targeted therapy and immunotherapy drug classes where there is significant potential for advancing pharmacodynamic therapeutic drug monitoring approaches to deliver effective treatments.

\section{The Challenges of Monitoring Drug Pharmacodynamics in Cancer Patients}

Murine models play a vital role in the development of novel cancer therapies, including the identification and validation of potential biomarkers for monitoring pharmacodynamic responses in patients. ${ }^{2,3}$ Acquisition of multiple tissue samples from mice, optimisation of tissue processing methods and the development of robust methods for measuring pharmacodynamic effects of novel agents directly in tumour can be performed with relative ease. However, successful translation of pharmacodynamic biomarkers from mouse studies 
into patients can pose a significant challenge. Ideally, pharmacodynamic studies within clinical trials are based on analysis of target engagement in tumour biopsies taken prior to and following treatment. With the exception of haematological malignancies, where repeated sampling of blood pharmacodynamic marker analysis during therapy is feasible, it is challenging to collect serial biopsies from patients with solid tumour cancers because of the invasiveness of the biopsy procedure. Furthermore, tumour heterogeneity between biopsy samples, even from the same patient, can complicate the interpretation of pharmacodynamic biomarker assay data. For these reasons, many clinical trials use alternative tissues such as blood, skin or plucked hairs as a surrogate for the measurement of pharmacodynamic responses in patients. The most commonly used tissues are discussed below, with a more exhaustive list of the wide range of sample types available for pharmacodynamic biomarker studies summarised in Table 1.

\section{Blood}

Blood-derived samples are the most commonly used tissue surrogates for pharmacodynamic biomarker analysis within clinical trials. This is predominantly due to the ease with which serial samples can be collected, processed and stored for future analysis. For cancer therapies, blood-borne markers of cell apoptosis and/or necrosis in plasma or serum are often measured to provide an indication of an anti-tumour effect. Cytokeratin 18 (CK-18) is an example of a well-established blood-borne biomarker of epithelial cell necrosis and/or apoptosis. ${ }^{4}$ The amount of circulating full-length and caspase-cleaved CK-18 across the course of chemotherapy treatment can be measured in serum or plasma samples collected across treatment cycles using enzyme-linked immunoassays. ${ }^{5,6}$ Baseline levels of CK-18 in blood are typically low but the amount of caspase-cleaved CK-18 fragments can increase during anticancer therapy. Since drug-induced apoptosis/necrosis of tumour cells is a common endpoint of all anti-cancer agents, measurement of CK-18 and CK-18 fragments in plasma or serum can be a useful means to monitor for anti-tumour effects of different classes of anti-cancer drugs across a wide range of tumour types, ${ }^{7}$ including pancreatic, ${ }^{8}$ lung, ${ }^{9}$ breast, ${ }^{10}$ testicular $^{11}$ and gastric $^{12}$ cancers. This area is discussed in more detail later in the review. 
Blood can also be used as a surrogate for pharmacodynamic monitoring of molecularly targeted anti-cancer drugs within clinical trials. However, it is essential to first confirm that drug-induced pharmacodynamic changes can be robustly measured using a suitable assay. Pre-validation studies using blood from mouse models or volunteers are typically performed to determine blood biomarker and assay suitability. Secondly, the degree of correlation between pharmacodynamic responses measured in blood and those measured directly in tumour tissue should be established. As an example, clinical trials of poly(ADP-ribose) polymerase (PARP) inhibitors in cancer patients have used peripheral blood mononuclear cells (PBMCs) as a surrogate tissue to monitor for pharmacodynamic effects. ${ }^{13,14}$ Preclinical mouse models were initially used to establish methods for measuring PAR levels in tumour tissue by ELISA. ${ }^{15,16}$ The PAR ELISA method was adapted for blood samples using human PBMCs cultured ex vivo, and the effects of PARP inhibitors tested to determine whether these agents exerted comparable effects in PBMCs as in tumours. ${ }^{17}$ In a phase I trial of olaparib, 90\% inhibition of PARP activity was observed in PBMCs obtained from patients treated with $60 \mathrm{mg}$ of drug or more, confirming drug-target engagement. ${ }^{12}$ Furthermore, the relationship between PARP inhibition in PBMCs and drug exposure was established. Immunoblotting of PAR levels in cell extracts isolated from paired tumour biopsies pre-treatment and after olaparib treatment was also confirmed. Thus, target engagement markers in blood helped to establish that olaparib had acceptable pharmacokinetic and pharmacodynamic properties and informed dose selection for later phase clinical studies.

Immune checkpoint inhibitors, such as anti-CTLA4, anti-PD-1 and anti-PD-L1 antibodies, have recently emerged as an important new class of anti-cancer agents. Checkpoint inhibitors block the interaction between T cells and their inhibitory receptors expressed within tumours. The study of immune cell populations in patient blood prior to and during checkpoint inhibitor treatment to discover biomarkers to predict for response or resistance to treatment is an area of intense research. ${ }^{18}$ Circulating lymphocytes, neutrophils, eosinophils and monocytes have been monitored for evidence of pharmacodynamic responses to checkpoint inhibition. For example, successful treatment with the anti-CTLA4 antibody, ipilimumab, is associated with increased levels of circulating lymphocytes ${ }^{19-22}$ and, specifically, an increase in CD4 T cells expressing inducible co-stimulator (ICOS). ${ }^{23}$ In cancer patients, flow cytometry analysis of 
circulating $T$ cells further indicated that an increased frequency of ICOS+ CD4 T cells can be used as a reproducible pharmacodynamic biomarker of anti-CTLA4 therapy. ${ }^{24}$ In this study, the ICOS+ CD4 T cell flow cytometry assay was found to correctly detect patients with a response of $71 \%$, after two administrations of ipilimumab. Other blood-circulating biomarkers that are reported to be associated with response to anti-CTLA4 treatment include depletion of Treg cell numbers, ${ }^{25}$ a combination of low lactate dehydrogenase, absolute monocyte counts, monocytic myeloid derived suppressor cells, high absolute eosinophil counts and relative lymphocyte counts and Treg frequencies. ${ }^{26}$ In another study, melanoma patients treated with ipilimumab exhibited upregulation of Ki67, ICOS and Gata3 expression on CD4+ and CD8+ T cells isolated from blood, providing potential pharmacodynamic biomarkers of anti-CTLA4 therapy. ${ }^{27}$ Studies aiming to identify blood-borne markers to predict and monitor clinical response to anti PD-1/PDL-1 blockade have also focused on changes in $\mathrm{T}$ cell populations. In non-small cell lung cancer (NSCLC) patients, an increase in Ki67+ PD1+ CD8 T cells was observed in the majority of patients following treatment with anti-PD-1 targeted therapies. ${ }^{28}$ In summary, analysis of peripheral blood cell populations as markers to monitor response to checkpoint inhibition is still an evolving area. However, given the complexity of the immune system and the fact that the tumour can evade the immune system by multiple mechanisms, developing blood-based biomarkers may help decipher each patient's immune system abnormalities and hence provide valuable information on response to immunotherapies.

Skin

Skin biopsies are more difficult to obtain than blood samples but represent a useful tissue surrogate for the monitoring of therapies in patients. ${ }^{29}$ The epidermis of the skin contains a basal layer of proliferating keratinocytes, including a population of stem cells which retain the ability to self-renew. ${ }^{30}$ Unlike blood, which contains a predominantly differentiated cell population, skin cells functionally express developmental signalling networks and these networks involve molecular targets identified in tumours or involve pathways which are likely to be altered by anti-cancer therapy. ${ }^{29}$ Thus, skin biopsies can be an ideal surrogate tissue for measuring drug pharmacodynamic responses in cancer patients for drugs that target cell cycle pathways, DNA damage repair pathways, Notch signalling, Wnt, Shh/Dhh, retinoic acid and 
epidermal growth factor (EGF) pathways. ${ }^{29}$ For example, early phase clinical studies of EGF receptor inhibitors have exploited involvement of the EGF pathway in skin homeostasis, repair and regulation of keratinocyte stem cell function. ${ }^{31}$ Biomarkers of EGFR pathway blockade including inhibition of EGFR auto-phosphorylation, phosphorylation of mitogen activated protein (MAP) kinase and alterations in Akt and p27 levels, were initially established in tumour cell lines and tissues using preclinical models. ${ }^{32,33}$ These same markers were then evaluated in normal skin samples obtained from cancer patients enrolled in phase I studies of the EGFR inhibitors erlotinib (OSI-774) and gefitinib (ZD1839), to study the relationship between dose and target engagement. ${ }^{34-36}$ In a study by Malik et al, ${ }^{34} 28$ patients with advanced cancer underwent skin biopsies at baseline and again after the last dose of the first cycle of treatment with erlotinib. The expression and phosphorylation of EGFR, MAP kinase and p27 in skin were assessed by immunohistochemical staining. Following erlotinib treatment, a significant decrease in phospho-EGFR expression in skin and an increase in the mean numbers of skin cells with nuclear staining for p27 were observed. However, a treatment-related change in MAP kinase phosphorylation was not seen. Furthermore, of these EGFR inhibitor responsive markers, only p27 expression showed any relationship to the administered dose of erlotinib. Based on these data and the simplicity and reliability of the method to measure p27 expression, the authors concluded that this was the most promising biomarker of EGFR inhibition for use in phase II studies with erlotinib. This study nicely illustrates that early evaluation of multiple potential biomarkers in phase $I$ is an important step for identifying the most relevant tissue surrogates and biomarkers for monitoring drug pharmacodynamics.

\section{Hair Follicles}

The human hair follicle contains proliferating cells and is therefore another source of tissue with the potential to be used for analysis of pharmacodynamic markers in response to anticancer drug treatment. A major advantage of hair follicles as a tissue surrogate is that they are extremely easy to collect from patients and animal models. Unlike skin and blood, hair follicle bulbs contain proliferating epithelial stem cells which control the growth and cycling of hair. ${ }^{37}$ Since hair follicle stem cells are constantly undergoing a process of cell division, these cells are thought to be particularly useful for measuring gene expression and/or protein 
changes to anti-cancer agents that disrupt DNA synthesis/repair and the cell cycle. Examples of biomarkers relating to cell cycle and DNA-repair pathways that are typically measured in hair follicles include Ki67, pRb, p27/phospho-p27 and $\mathrm{y}^{\mathrm{H}} 2 \mathrm{AX} .{ }^{38}$ Phosphorylated H2AX ( ${ }^{-}$ $\mathrm{H} 2 \mathrm{AX}$ ) is a marker of the formation of DNA double-strand break repair complexes ${ }^{39,40}$ and is often used to assess the effects of therapies that inhibit DNA repair, including PARP inhibitors such as olaparib. In a phase I study of olaparib in cancer patients, induction of $\mathrm{Y}-\mathrm{H} 2 \mathrm{AX}$ foci was observed in plucked eyebrow hair follicles collected 6 hours post-treatment. ${ }^{12}$ Furthermore, induction of $\mathrm{y}-\mathrm{H} 2 \mathrm{AX}$ foci was observed at all doses tested and was sustained at later time points. These data demonstrated that PARP inhibition causes induction of collapsed DNA replication forks and DNA-double strand breaks, confirming the predicted mechanism of action for olaparib. In addition, these pharmacodynamic data were used to inform dose selection of olaparib for subsequent clinical studies.

Plucked hair follicles have also been applied as a surrogate tissue for biomarker analysis of the effects of PI3 kinase inhibitors, ${ }^{41}$ Akt inhibitors ${ }^{42}$ and cyclin-dependent kinase (CDK) inhibitors. ${ }^{43}$ In a phase I healthy volunteer study of the CDK inhibitor AZD5438, the pharmacodynamic effects of the drug were assessed in plucked hairs from the scalp. ${ }^{43}$ Volunteers were given single oral doses of $\operatorname{AZD} 5438(10,40,60 \mathrm{mg}$ or placebo), with hair pluckings taken before each dose and again at 1.5, 6 and 24 hours post-dose. Expression of the CDK pathway biomarkers, phospho-pRB, Ki67 and phospho-p27 were assessed using immunohistochemistry (IHC) methods. Ten hair pluckings were used for each biomarker but hair wastage was observed during processing of the samples and quantitative IHC data were obtained for around $70-80 \%$ of the samples. The authors noted that different sections of hair have different proliferative potential along the hair sheath ${ }^{44}$ and this is an important factor to take into account when interpreting quantitative data on biomarkers of proliferation. They also found that a significant proportion of the hairs had no nuclear staining at all for each marker and it was felt that this was unrelated to the drug effect but instead reflected the stage of hair growth. These negatively-stained hairs were assumed to be processing failures and were excluded from the final analysis. In spite of these challenges, levels of phospho-pRB, Ki67 and phospho-p27 were altered at 1.5 and 6 hours post-dose with AZD5438, although the changes observed were not statistically significant. This study demonstrates some of the technical challenges associated with biomarker analysis using hair follicles. Each hair follicle 
bulb contains a relatively small population of proliferative cells, therefore robust signal detection can be difficult. Wastage of hair follicle samples will occur during sample processing and sectioning of hair follicles to prepare slides suitable for microscopy-based techniques is challenging. ${ }^{38}$ As well as heterogeneity in stages of cell proliferation along the length of a single hair shaft, heterogeneity exists between follicles collected from different regions of the body. For example, scalp hair is reported to have higher expression levels of Ki67, total p27 and phospho-p27 in comparison to eyebrow hair. ${ }^{38}$ In summary, plucked hairs are potentially attractive as readily accessible surrogate tissue for monitoring the effects of anti-cancer drugs due to their ease of collection, but suffer from a number of technical drawbacks. Advances in processing methods and the development of techniques which provide higher analytical sensitivity may aid the success rate of hair follicle-derived biomarker assays.

\section{The Promises of Circulating Biomarkers}

Determining the efficacy of potential or existing therapies in cancer often requires physical examination, access to patient tissue or tumour samples to assess changes in the molecular profile, imaging to monitor the presence of disease over time and the use of serological markers. Obtaining tumour biopsies for many malignancies is uncomfortable for the patient, risks further complications and is costly. Imaging alone can be challenging in cancers such as glioblastoma multiforme (GBM) where evidence of pseudo-progression can complicate diagnosis. ${ }^{45}$ Furthermore, current assays for circulating tumour markers, such as carcinoembryonic (CA 15-3) and muc-1 (CA 27.29) antigens in breast cancer or prostate specific antigen (PSA) in prostate cancer, often lack the necessary specificity. ${ }^{46}$

The ultimate goal in oncology is to validate the use of circulating biomarkers as surrogate endpoints of tumour burden or disease progression during treatment and to monitor the molecular profile of tumours in real time for evidence of the emergence of drug resistance. The relative ease of taking multiple blood samples or 'liquid biopsies' throughout treatment has the potential to allow for decisions to be made on whether to discontinue or alter treatment. This section explores the promise of circulating microRNAs (miRNAs), circulating tumour cells (CTCS), and circulating tumour DNA (ctDNA) in this endeavour and the challenges that are still faced in fully validating these approaches. 
microRNAs

MicroRNAs are small non-coding RNAs (18-25 nucleotides) that are negative regulators of gene expression. ${ }^{47}$ The ability to measure the expression of these molecules in a variety of tissues and bodily fluids, in addition to the discovery that unique microRNA signatures can classify different cancers, ${ }^{48,49}$ has led to huge interest in their potential as biomarkers. Circulating miRNAs have been described as possible non-invasive diagnostic, prognostic and predictive biomarkers in oncology.

As a prognostic tool, Lawrie et $\mathrm{al}^{50}$ in their initial discovery of stable miRNAs in the circulation, reported that high miR-21 expression in serum was associated with improved relapse-free survival time in patients with diffuse large B cell lymphoma (DLBCL). In pancreatic cancer, Ali et $\mathrm{al}^{51}$ additionally showed that increased plasma miR-21 expression was associated with worse patient survival and drug resistance in vitro, suggesting a possible role for miR-21 in predicting tumour aggressiveness.

Since 2008 there have been scores of studies investigating the potential for utilising information relating to circulating miRNAs to support the decision making process in cancer treatment. In studies investigating circulating miRNA markers of treatment response, Cui et $\mathrm{al}^{52}$ reported high serum miR-125b expression to be significantly associated with nonresponse to cisplatin-based chemotherapy in patients with NSCLC, whilst high levels of miR200c in serum were reported to be correlated with poor response to cisplatin and 5fluorouracil-based chemotherapy in oesophageal cancer patients. ${ }^{53}$

The identification of miRNAs that monitor tumour burden and disease progression throughout the treatment of a patient is an important avenue that may have potential for drug monitoring. Greystoke et $\mathrm{al}^{54}$ showed in CDX mouse models of small cell lung carcinoma (SCLC) that circulating miR-95 detected in tail vein plasma was a sensitive monitor of tumour growth and was detectable before measurable tumours were observed. Subsequently, they selected a panel of 10 miRNAs (miRs-95, 141, 195, 200a, 200b, 200c, 210, 335, 375, 429) that were elevated in SCLC, NSCLC, colorectal and pancreatic cancer patients as compared to healthy volunteers and was more accurate at distinguishing between low and high tumour 
burden patients. Furthermore, levels decreased post-treatment, with larger changes seen in patients who showed greater clinical response.

Circulating miRNAs have also been described as potential markers of drug toxicity. For example, levels of miR-122 measured in plasma are an early detector of liver injury caused by acetaminophen (paracetamol) poisoning, outperforming alternative clinical tests. ${ }^{55}$ An ongoing clinical study aims to further explore the use of serum miR-122 as a real-time marker of chemotherapy-induced liver toxicity (NCT03039062). ${ }^{56}$ Additionally, Zhao et al ${ }^{57}$ reported that elevated levels of circulating cardiac miRNAs (miR-1254 and miR-579) were found in patients with cardiotoxicity following administration of bevacizumab.

\section{Circulating tumour cells}

Circulating tumour cells (CTCS) originating from solid tumours are present in the peripheral blood and are believed to provide a mechanism for depositing metastases at distant sites. ${ }^{58}$ Although they were first described as early as 1869 by Thomas Ashworth, their clinical utility has only started to gain attention in recent years, as isolation and detection methods and single cell analysis have improved. CTCs have subsequently been described as potential prognostic, predictive and disease monitoring endpoints through CTC enumeration and molecular characterisation.

Many techniques that allow for the isolation of CTCs have been described, including immunemagnetic isolation and methods that isolate cells based on size, deformability and density. ${ }^{59}$ The CellSearch method is an immune-magnetic method for isolating CTCs whereby epithelialderived cells in the circulation are enriched by capturing those expressing EpCAM. CTCs are further identified by looking for EpCAM-positive cells expressing cytokeratin but not the leukocyte-associated CD45. ${ }^{60}$ This method was used to show that enumeration of CTCs was a reliable prognostic indicator in metastatic breast, ${ }^{61,62}$ prostate $^{63}$ and colorectal cancer patients, ${ }^{64}$ both before and during treatment. As a result the use of CellSearch to enumerate baseline CTC numbers has been cleared by the FDA for prognostic use. Although these studies did not specifically evaluate whether patients with an elevated CTC count might benefit from other therapies, it raises the question as to whether CTC enumeration could act as a surrogate endpoint for efficacy and potentially guide the decision to discontinue ineffective treatment. 
Using an alternative technical approach, Ogle et $a^{65}$ used imaging flow cytometry to identify hepatocellular carcinoma (HCC) derived CTCs based on immunofluorescence of the epithelial markers cytokeratin and EpCAM, as well as HCC specific markers AFP and glypican-3, and DNA-PK, a candidate biomarker for treatment stratification in HCC. CTCs were additionally identified based on size, morphology and DNA content. However a proportion of cells were found not to express any of the CTC markers and had to be identified based on size and the absence of CD45 positivity. This brings into question what the consensus should be when trying to accurately define the presence of a CTC in analysis, as a reliance of epithelial markers may exclude a proportion of the CTC population. In order to address the issue of 'epitope bias' in CTC enrichment, several groups have recently developed methods using the Parsortix system, which enriches CTCs based on size and rigidity. Chudziak et al, ${ }^{66}$ in a preliminary clinical study, were able to develop a method whereby 20 or more CTCs were identified in all 12 samples enriched by Parsortix, whereas 2 samples enriched by CellSearch in the same 12 samples showed no CTCs and an additional 3 samples contained fewer than 5 CTCs.

Mutational analysis in CTCs may also reveal key information relating to the effect of treatment on sub-populations of CTCS. A study in metastatic NSCLC patients reported that a majority of patients who showed clinical tumour progression whilst receiving tyrosine kinase inhibitors (TKIs) also had CTCs with the acquired EGFR kinase domain T790M drug resistance mutation. ${ }^{67}$

\section{Circulating tumour DNA}

The presence of DNA in the circulation is another marker that could be exploited for disease monitoring and prediction of treatment response. Circulating free DNA (cfDNA) is thought to be released into the bloodstream following cell death (either apoptosis or necrosis) ${ }^{68}$ although there is some evidence that cfDNA could also be actively secreted. ${ }^{69}$ The discovery of common cancer mutations in cfDNA increased the interest of using circulating tumour DNA (ctDNA) as a potential non-invasive diagnostic tool. Advances in technologies have allowed for the detection and quantitation of mutant alleles by digital drop PCR (ddPCR) ${ }^{70}$ and next generation sequencing of circulating DNA has heralded the detection of multiple mutations, ${ }^{71}$ chromosomal aberrations, $^{72}$ focal amplifications ${ }^{73}$ and gene rearrangements ${ }^{74}$ in cancer patients. 
The analysis of ctDNA has been shown to be important for overcoming the issue of heterogeneity in tissue biopsies, whereby the many clones that may be present in a patient can be monitored. Furthermore, there is evidence that resistant sub-clones can be detected at the beginning of a study and can increase many months before clinical progression. Diaz et $\mathrm{al}^{75}$ reported increasing amounts of mutant KRAS ctDNA in the serum of patients with colorectal cancer who were receiving anti-EGFR therapy and who were originally identified as having KRAS wild-type tumours. Dawson et al $^{76}$ additionally showed in patients with metastatic breast cancer that ctDNA in plasma showed a greater sensitivity and better correlation with changes in tumour burden than other circulating biomarkers, as well as providing the earliest measure of treatment response. These examples highlight the potential that ctDNA analysis has in monitoring changes in disease burden, subclinical responses to therapy, and drug resistance. These factors may prove vital in determining an optimum therapeutic dose during pharmacodynamic monitoring of existing and future targeted therapies. At present the use of ctDNA to help select patients with EGFR-mutant NSCLC for specific targeted therapy has been approved by the EMA and FDA if a tumour sample is unavailable.

The challenges for establishing circulating biomarkers in TDM

The potential of cancer specific circulating nucleic acids and CTCs as useful diagnostic, prognostic and predictive cancer biomarkers, as well as toxicity markers, is becoming well established. Their use in therapeutic drug monitoring of new and existing cancer therapies will depend on the success of being able to reliably incorporate these new tests into established PK/PD models. Another major challenge is the pre-analytical and technical variation in the literature, making robust validation challenging.

In miRNA studies a consensus is needed for factors such as i) choice of technology used to quantify miRNAs, ii) method of normalisation and iii) methodology for sample collection and processing. Expression of miRNA can be affected by patient factors such as age, comorbidities, and current medication, ${ }^{77}$ highlighting the need to cut through the 'noise' and identify vital disease or toxicity specific miRNAs. A consensus is similarly required for what exactly constitutes a CTC. Despite the FDA-approved CellSearch method, there needs to be an 
assurance that a chosen method isolates all populations of CTCS and that this method is sensitive enough for cancers where CTC count is typically low. The standardisation of blood collection, storage and processing protocols that are convenient in clinical practice will aid in further establishing this promising area of biomarker research.

\section{Clinical Toxicity as a Pharmacodynamic Biomarker}

One of the main reasons to use biomarkers in a clinical setting is to prevent or lessen the toxic side effects of anti-cancer drugs. In the field of oncology many conventional drugs, but also newer targeted agents, are known to be associated with severe side effects including myelosuppression, hypertension, thyroid dysfunction and cardiotoxicity. ${ }^{78,} 79$ In multi-drug therapy, co-administered agents can often share overlapping adverse effects. Therefore a single biomarker for a specific toxicity could simplify clinical monitoring, as opposed to numerous biomarkers for each individual drug. The successful implementation of such biomarkers could reduce toxicity and increase efficacy, if informed decisions are taken in response to changes in these clinical parameters.

\section{Cardiotoxicity}

Due to the prolonged survival rates of cancer patients, long-term side effects including cardiotoxicity are becoming increasingly important considerations. ${ }^{80-82}$ Various drugs, including anthracyclines and trastuzumab, can cause alterations in cardiomyocytes through different mechanisms. ${ }^{83-85}$ During treatment with trastuzumab a reversible decrease in Left Ventricular Ejection Fraction (LVEF) ${ }^{86}$ is commonly observed. Therefore a 3-monthly LVEF ${ }^{87}$ evaluation plan is established to minimise treatment-associated cardiotoxicity. There are attempts to optimise and individualise these protocols ${ }^{88}$ to reduce the burden of unnecessary over-examination for low-risk patients, but this still includes time consuming echocardiography.

Whereas heart failure due to trastuzumab is often reversible, patients treated with anthracyclines mostly suffer from a chronic version of heart failure. ${ }^{84}$ In reaction to this a 
maximum cumulative lifetime ${ }^{89,90}$ dose is commonly defined to reduce risk of developing such toxicity. However, these approaches are not adaptive and the need for a personalised monitoring regimen is evident. In the field of cardiology alternative biomarkers to LVEF are widely used to determine heart function. Troponins are responsible for calcium-regulated muscle contraction ${ }^{91}$ and the cardiac specific isoforms, cardiac Troponin I (cTnI) and T (cTnT), are established biomarkers for diagnosis and prognosis ${ }^{92-94}$ of cardiomyocyte damage, e.g. myocardial infarction and heart failure. The precursor of the B-type natriuretic peptide, NTproBNP, is another wide spread biomarker for the diagnosis and follow-up of heart failure. ${ }^{94}$ It is specific for cardiomyocytes where it is synthesised in reaction to dilatation of the heart muscle. ${ }^{95}$ The major advantage of these biomarkers is their potential to identify changes in heart muscle structure (cTnI and cTnT) and function (NP-proBNP) before they are clinically manifested in the form of a reduction in LVEF. In a study involving 703 cancer patients, it was shown that high levels of cTnl have a significant prognostic value in cardiac risk stratification following chemotherapeutic treatment. ${ }^{96}$ Similarly, cTnT is a good predictive marker determining whether HER2-positive breast cancer patients treated with trastuzumab are likely to suffer from heart failure, as a recent study suggests. ${ }^{97}$ The same study showed that increases in NT-proBNP levels are associated with significant decreases in LVEF.

A pharmacodynamic modelling approach ${ }^{98}$ of these biomarkers in breast cancer patients undergoing treatment with anthracyclines or trastuzumab, demonstrated a correlation between changes in troponin levels and the effect on LVEF. Furthermore, the optimal time for cTnl quantification was shown to be the last day of treatment, since the predictive peak concentration is reached at this point. Finally, the model showed that other risk factors, such as age, other cardiac diseases and dosing intervals, could not be identified as covariates.

Whereas in conventional pharmacokinetic TDM the reaction to suboptimal plasma concentrations is an adaptation of the dosing regimen, in TDM approaches based on toxicity pharmacodynamic endpoints, other options for intervention can be considered. Although there are currently no clinical trials to confirm the effectiveness of drugs used for treating heart failure in this setting, a prospective study on 2625 patients receiving anthracyclines 
against solid tumours indicated that heart function is likely to improve when treated with an angiotensin-converting-enzyme (ACE) inhibitor. ${ }^{99}$

To confirm the promising data presented above two clinical trials are currently ongoing. The Patients Undergoing AnthRacycline-Based Chemotherapy to Assess the Effectiveness of Using

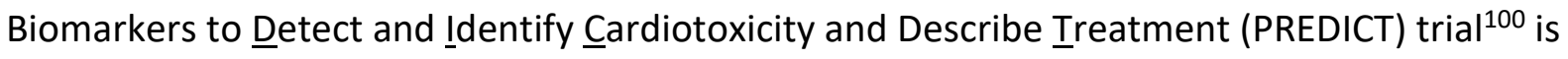
a multicentre interventional study involving 597 cancer patients. The feasibility of measuring BNP and cTnl for identifying patients that will develop cardiotoxicity in the course of anthracycline treatment is being assessed. A recently published interim analysis demonstrated the applicability of non-invasively derived echocardiogram measurements as an indicator for predicting such toxicities. Furthermore, the aim of a prospective cohort study ${ }^{101}$ on 35 patients is to show that early changes in biomarkers of stress (NT-proBNP), fibrosis (galectin-3), necrosis (troponin) and inflammation (ST2) are predictive for changes in LVEF. Both studies are expected to provide guidance for the implementation of new monitoring approaches for clinical use.

\section{Hypertension}

Another commonly observed adverse effect on the cardiovascular system during chemotherapy is the induction of hypertension. Vascular endothelial growth factor (VEGF) inhibitors such as bevacizumab, sunitinib and sorafenib are associated with an increased risk of developing reversible hypertension, ${ }^{102-104}$ the mechanism for which is directly linked to the mechanism of action. By inhibiting the VEGF receptor, endothelial function and nitric oxide synthesis are affected, which leads to vasoconstriction and the reduction of vascular permeability. ${ }^{105-107}$ Some studies have shown that patients treated with sunitinib are more likely to have better overall survival and progression free survival when blood pressure increases during treatment. ${ }^{108,109}$ This link could potentially be used to discriminate patients that are more likely to benefit from treatment with VEGF inhibitors. ${ }^{110,111}$ More research needs to be conducted to find specific cut-off levels of blood pressure increase that indicate changes in dosing or even a change of the drugs used. Furthermore, potential confounding factors including age, metabolic diseases and smoking should be included. 
The use of alkylating agents and related drugs such as cisplatin, have also been associated with the development of high blood pressure following chemotherapy ${ }^{112}$. Nephrotoxicity and direct damage on the endothelial function are proposed mechanisms of inducing hypertension. ${ }^{113,114}$ In this respect biomarkers of nephrotoxicity such as creatinine clearance are a helpful tool to monitor kidney function over time, while kidney injury molecule-1 (KIM1), cystatin C or albumin could indicate early damage of the nephron. ${ }^{115,116}$ A specific biomarker of endothelial function, microalbuminuria occurs in a fifth of patients treated with cisplatin, ${ }^{117}$ but its clinical utility needs to be investigated in future studies.

\section{Thyroid dysfunction}

Many chemotherapeutic drugs can have adverse effects on the thyroid glands, especially targeted and immunological therapies. Between $32-85 \%$ of patients treated with sunitinib have been reported to suffer from hypothyroidism, but other tyrosine kinase inhibitors, like imatinib, dasatinib, nilotinib and sorafenib, are also known to have negative effects on the thyroid glands ${ }^{118-121}$. The exact mechanism of this effect is still unknown ${ }^{122}$, but capillary regression, antibodies against the thyroid peroxidase or decreased iodine intake have all been suggested ${ }^{123}$.

The thyroid hormones (triiodothyronine $\left(T_{3}\right)$ and thyroxine $\left(T_{4}\right)$ ) play a major role in regulating metabolism. High serum levels of $T_{3}$ and $T_{4}$ cause elevated blood pressure, tremor, a rapid heart rate and weight loss, whereas low levels can be mistaken for symptoms commonly associated with chemotherapy, such as fatigue, weakness, memory loss and depression. An effect on drug metabolism might also play a role in how well treatment is tolerated. ${ }^{124,125}$ The thyroid hormones and thyroid-stimulating hormone (TSH) can easily be monitored, with the individual levels as compared to each other being used to distinguish between different thyroid conditions. There is currently no universal evidence to guide which patients should be treated with levothyroxine. In this respect, it has been suggested by Hamnvik et al. that hypothyroidism should only be treated with substitution therapy when TSH-levels exceed 10 
$\mathrm{mIU} / \mathrm{L}$ and $\mathrm{T}_{4}$ levels are low. ${ }^{119}$ Levothyroxine is generally well tolerated and symptoms of fatigue can be lessened. ${ }^{121}$ For more detailed guidance it may be helpful to develop a PK/PD model that includes the complex quantity of confounding factors and individual risk of the many drugs that affect thyroid function.

\section{Cell Death}

CK-18 is a protein predominantly found in the cytoskeleton of the epithelia that is released into the bloodstream during various forms of cell death. ${ }^{126}$ Depending on the mechanism, either the caspase-cleaved M30 fragment or the M65 fragment of CK-18 can be detected. Whereas M65 can be measured when cells are dying due to apoptosis and necrosis, the presence of M30 indicates cell death through apoptosis. ${ }^{127}$ The ratio of these two fragments could help to identify how cells are affected by different drugs. Because the eradication of tumours goes hand in hand with cell death, various studies have been carried out to investigate CK-18 as a prognostic biomarker for solid cancers, showing non-concordant outcomes. ${ }^{7,128-131}$ The combination of multiple drugs with a variety of molecular mechanisms and small cohort size could explain inconsistencies in the results obtained. The potential for using CK-18 fragments in lymphomas represents a different approach, as CK-18 as an epithelial specific protein is not found in lymphoid cells. Therefore it could potentially be used to determine chemotherapy-induced cytotoxicity in patients with this disease type. A study of patients with different forms of lymphoma showed that geometric mean baseline concentrations of M65 were comparable to healthy individuals and markedly lower than patients with epithelial cancer. ${ }^{132}$ Changes in M65 concentrations to baseline concentrations after treatment were compared. It was shown that larger increases in CK-18 on day three of a treatment cycle were associated with subsequent epithelial toxicity. Whether this can also be used in a pharmacodynamic therapeutic drug monitoring setting needs to be investigated in future studies. Elevated plasma concentrations of CK-18 are also known to be a biomarker for many liver problems, for example non-alcoholic fatty liver disease (NAFLD). ${ }^{133}$ A PK/PD model and a large cohort study would be useful to find confounding factors and to show clinical relevance, specificity and selectivity of predicting toxicity with CK-18. 


\section{Skin Toxicity}

Another field of biomarker monitoring is the use of non-invasive Raman spectroscopy to detect skin toxicity caused by TKIs. This approach is particularly relevant to patients treated with EGFR inhibitors, but drugs that inhibit MAP- and BRAF-pathways, are also associated with dermal reactions. ${ }^{134-136}$ The incidence of cutaneous side effects is $66-75 \%$ for the EGFR inhibitors erlotinib ${ }^{137-140}$ and gefitinib ${ }^{141-143}, 16-45 \%$ for the BRAF inhibitors vemurafenib and dabrafenib ${ }^{144}$ and $9-45 \%$ for the MAP inhibitor selumetinib, ${ }^{145}$ dependent on cancer type and drug. The EGFR pathway regulates cell survival, cell migration and differentiation. Following inhibition of the EGF receptor in mice, skin homeostasis is disrupted by an increase in necrosis factor alpha and interleukin-1, which promote inflammation and cell death ${ }^{146,147}$. This mechanism explains the on-target side effect of EFGR inhibitors and supports the potential use of cutaneous abnormalities as an indicator of drug efficacy. ${ }^{148-151}$ Ideally the toxicity is not fully developed when an intervention is made. A recent pilot study showed that Raman spectroscopy could discriminate between affected and healthy skin. ${ }^{152}$ The key advantage of this approach is to detect information that is unreachable on a histologic level without the need for a biopsy.

\section{Pharmacokinetic/Pharmacodynamic Modelling Approaches}

Given the toxicity of most anti-cancer agents, adapting dose and/or schedule for a given patient is a potentially crucial issue. Decreasing dose or spacing out administration is frequently perceived as pejorative by clinicians unless a severe toxicity is present. Nevertheless, empirical alternative schedules or reduced/adapted dosing can represent genuine alternatives. For instance, in patients with renal cell carcinoma receiving sunitinib, an alternative 2 weeks on/ 1 week off schedule has been proposed by Atkinson et al, ${ }^{153}$ who reported that this adapted schedule resulted in better progression-free survival (PFS) and overall survival (33 months versus 18 months; $p<0.0001$ ) compared to results obtained with standard dosing guidelines. While this example illustrates an empiric success, modern tools like computational pharmacology can surely help clinicians identify better schedules of drug administration. 
The ever-increasing power of computer software has facilitated the use of mathematical models to play a growing role in the cancer field. While computational oncology has mostly focused on cancer biology and systems biology studies, ${ }^{154}$ computational pharmacology has recently emerged as a new strategy to help better use anti-cancer agents. ${ }^{155}$ Computational pharmacology certainly has the potential to support daily clinical practice through the personalisation of treatment. To improve the efficacy/toxicity balance through adjustment of drug doses and schedules beyond serendipity or empiricism, computational pharmacology relies on modelling of PK/PD relationships. Indeed, mathematical models can be used to predict not only tumour responses and efficacy, but also toxicity during treatment planning or adaptation of doses. Computational pharmacology encompasses a wide variety of techniques ${ }^{155}$ ranging from very simple tools (e.g. geometric scale correcting factor or Bayesian estimation after therapeutic drug monitoring) through physiological models and highly sophisticated multiscale models such as the 'oncosimulator'. ${ }^{156}$ Among mathematical constructs, three main categories can be identified:

1) statistical learning algorithms that rely on biologically agnostic models leveraging largescale data into predictive signatures of value for improved classification of patients.

2) multiscale mathematical models that rely on an in-depth description of a large range of interacting biological processes, with the aim to better understand complex phenomena.

3) phenomenological models that have an intermediate complexity and use simplified yet mechanistic descriptions of the reality to provide concrete tools adapted to the sparsity of clinical data. This can provide practical solutions to clinical problems ranging from personalised prognosis of metastatic relapse to the adaptive scheduling of anti-cancer drugs (Figure 1).

These models can be applied to toxicities and/or the anti-tumour potential of a given treatment. As haematological side effects represent the dose-limiting toxicities of most cytotoxic drugs, they have been the focus of several models. In routine practice a blood count is performed immediately before the subsequent cycle of chemotherapy, since a normal count is required to administer the chemotherapy, or in the case of fever or bleeding when major neutropenia or thrombocytopenia is suspected. Until recently, PK/PD analysis was based on a two-stage approach. Firstly, by involving a summary of both pharmacokinetic and 
pharmacodynamic outputs for each patient: usually individual plasma drug exposure (AUC), and percentage decrease of neutrophil count (\%ANC) from baseline to nadir count; the second stage is the statistical step consisting of correlating AUC and \%ANC. This two-stage approach has several limitations: any missing blood count makes the patient non-evaluable, the duration of a critical count is not considered, and only baseline and nadir counts are taken into account. Several modelling approaches have been developed in order to circumvent these limitations. ${ }^{157-163}$ Some are strictly mathematical and simply allow transformation of the discrete values of ANC count into a continuous function (e.g. a cubic spline function ${ }^{162}$ ). The models proposed by Friberg et $\mathrm{al}^{163}$ and Meille et $\mathrm{al}^{161}$ may be qualified as semiphysiological models since they are based on the modelisation of different steps in the haematopoietic process. A model proposed by Fornari et al mimics the maturation chain of neutrophils based on five compartments. ${ }^{157}$ In the model proposed by Friberg et al, after drug administration, the cytotoxic effect of the drug (Edrug) on the proliferating neutrophil cells at any time, is proportional to the plasma drug concentration (Conc) according to the equation: Edrug $=$ Slope $x$ Conc; the slope corresponding to the patient sensitivity to the neutropenic effect of the cytotoxic agent. It is then possible to identify patient characteristics responsible for pharmacodynamic inter-individual variability by showing that typical values of Slope are related to these pharmacodynamic covariates. ${ }^{163}$ Schmitt et al ${ }^{164}$ proposed an optimal carboplatin AUC depending on the drug used in combination. Although this semi-physiological model has not been used to monitor patients routinely, ideally the sensitivity of each patient to chemotherapy would be determined after the first cycle, and the dose would be adapted for following cycles in order to achieve the acceptable toxicity. We may even consider using a K-PD approach (i.e. modelling of ANC profiles in the absence of drug concentrations) that spare any blood sampling and plasma drug analyses. However, such a protocol would require prospective validation to check both the robustness of the model and that intra-patient variability is limited.

Mathematical modelling can also be utilised to optimise the dosing or sequence of administration of anti-cancer agents. Thus, recently, a phenomenological model was used to optimise the dosing of gemcitabine in a neuroblastoma setting. ${ }^{165}$ The authors were able to predict the superiority of metronomic administration of gemcitabine over maximum tolerated dose (MTD) approaches, but also to optimise the dosing of metronomic 
gemcitabine. In vivo experiments in mice bearing neuroblastoma confirmed the prediction of the model in terms of superiority of the metronomic regimen and led to the use of 14-fold lower exposures of metronomic gemcitabine (AUC values of $10 \mathrm{vs} 0.69 \mathrm{mg} / \mathrm{mL} / \mathrm{min}$ ), while maintaining the same control of tumour growth. Elsewhere, a multiscale model was developed to describe the in vitro cellular dynamics of the EGFR-mutant glioma cell line, taking into account the heterogeneity of the cancer cells and the invasiveness of the disease and blood brain barrier following different lapatinib dosing schedules. ${ }^{166}$ The model predicted that continuous dosing was the most appropriate and clinically feasible strategy to both slow down tumour growth and decrease tumour burden.

The sequence of drug administration is also crucial. For instance, bevacizumab, an anti-VEGF antiangiogenic drug, is almost always administered in combination with chemotherapy. Interestingly, several teams have reported that bevacizumab could induce a transient phase of vascular normalisation, ${ }^{167}$ thus enabling a potentially better drug delivery when cytotoxic administration is adjuvant. Mollard et al ${ }^{168}$ developed a phenomenological model to simulate the anti-tumour activity of different sequences of administrations between bevacizumab and paclitaxel in breast cancer and predicted that the administration of bevacizumab followed by paclitaxel would lead to better outcome. The model could also estimate the most efficacious time interval between bevacizumab and chemotherapy, with two days representing the optimal gap between administration of the two drugs, yielding a $68.3 \%$ tumour size reduction when compared to the concomitant schedule. Interestingly, the model also predicted that in some cases, sequential schedules could be detrimental and lead to an increase in tumour size when compared with the concomitant schedule, such as an 8-day gap (+13.6\%). Most importantly, the predictions were then prospectively validated in vivo in a murine breast cancer model, in which the bevacizumab/paclitaxel sequence was statistically more efficient in terms of reducing tumor growth versus concomitant dosing, both at the end of treatment and at conclusion of the study. ${ }^{169}$

One of the greatest challenges is to apply and validate these models in the clinic as reliable approaches to drive patient treatment, with such experiences still relatively limited. In children with neuroblastoma, Panetta et al used mathematical modelling and simulation to assess the contribution of topotecan systemic exposure and scheduling on both the activity and the haematological toxicity of topotecan. They used PK and PD data obtained from a 
phase II study for paediatric patients with high-risk neuroblastoma and were able to show that the protracted administrations led to better control of tumour growth (-5\% vs $-65 \%$ with the same drug exposure). ${ }^{170}$ These findings were confirmed by Santana et al, who reported that protracted administration of topotecan in children with relapsing/refractory solid tumours using PK guided administration was feasible and safe. Of note, 5 partial responses were reported using this approach. ${ }^{171}$

Elsewhere, $\mathrm{Yu}$ et al published results from a phase I trial of evolutionary modelling-based dosing schedule combining pulsed and low dose erlotinib. ${ }^{172}$ The schedule was well-tolerated but did not improve progression-free survival or prevent emergence of EGFR resistant clones and therefore at first sight did not validate the mathematical predictions of the model. Nevertheless, the authors proposed that this was likely due to low peak serum concentrations of erlotinib. Moreover, the proposed schedule was able to prevent progression of untreated or any new central nervous system metastases in all patients.

In a phase $\mathrm{I} / \mathrm{II}$ trial in women with breast cancer, Henin et al ${ }^{173}$ validated a mathematicalbased model of densification/intensification of the combination of docetaxel/epirubicin. ${ }^{174}$ The optimised dosing regimen led to fewer toxicities and higher efficacy as compared with standard or empirical densified dosing. This study showed that model-driven dosage adjustment could lead to improved efficacy-toxicity balance in patients.

Recently, Barbolosi et al developed a mathematical model to optimise the dose and schedule of metronomic vinorelbine, taking into account both anticancer activity and haematological toxicities, which consisted of different dosing per day (60 mg on Day 1, $30 \mathrm{mg}$ on Day 2 and $60 \mathrm{mg}$ on Day 4 weekly versus the empirical $3 \times 50 \mathrm{mg} /$ week). ${ }^{175}$ The dosing regimen proposed by the model has been tested in a clinical trial and shown to be safe in patients with relapsing/refractory NSCLC or mesothelioma. ${ }^{176}$ Studies are currently ongoing to further explore the activity of the regimen.

\section{Drug Focus}

Within the world of oncology there are many different agents belonging to distinct drug classes which are used in the treatment of various types of cancer. The purpose of the current review is not to provide a detailed account of individual drugs which may have potential for 
future dosing based on pharmacodynamic characteristics. We have selected a targeted therapy for treating solid tumours (osimertinib), a targeted therapy used in haematology (ibrutinib) and an immunotherapeutic (pembrolizumab) which provide good examples of the current state of play regarding the potential utility of TDM based on pharmacodynamics in the modern era of cancer therapy.

\section{Osimertinib}

Activating mutations in the kinase domain (exon 18-21) of the EGF receptor are the canonical oncogenetic drivers of $15 \%$ (Europe) and up to $40 \%$ (Asia) of NSCLC and pave the way for using EGFR TKIs. ${ }^{177}$ Unfortunately, most NSCLC patients will relapse after 1st or 2 nd generation TKIs because of a variety of mechanisms of acquired resistance, including the EGFR T790M mutation. Osimertinib is a third-generation TKI that has shown selectivity against T790M plus other mutated forms of the EGF receptor, and is now considered as a mainstay for treating NSCLC patients that have progressed after 1 st and 2 nd generation TKIs, or for patients whose tumours exhibit de novo the EGFR T790M genotype. ${ }^{178}$

Osimertinib is an oral TKI exhibiting linear pharmacokinetics over the $20-240 \mathrm{mg}$ range. ${ }^{179}$ While relationships have been observed between osimertinib exposure and side-effects including rash, diarrhoea and corrected QT interval (QTcF), the therapeutic window of osimertinib is considered to be large and toxicities are limited following standard $80 \mathrm{mg}$ QD dosing. ${ }^{180}$ There are currently few recommendations regarding pharmacodynamic adaptive dosing of osimertinib. Initial $80 \mathrm{mg}$ QD dosing is recommended to be reduced to $40 \mathrm{mg}$ when increases in QT intervals greater than 500 ms over two consecutive electrocardiograms are observed. Any other toxicity of grade 3 or above should lead to empirical treatment discontinuation and reintroduction of the drug at a lower dose if the condition improves to grade $0-2$ after withholding osimertinib for 3 weeks.

Monitoring osimertinib efficacy is mostly based upon RECIST evaluation 3 months after treatment initiation and radiologic evidence of complete or partial response, both in terms of the main tumour and metastatic sites. Should the patient progress, re-checking for the T790M mutational status or EGFR amplification, e.g. using liquid biopsies, is strongly encouraged. ${ }^{181}$ Clonal evolution of NSCLC calls indeed for regular re-appraisal of the 
molecular and genomic status of the new main dominant clone when targeted therapies are used. ${ }^{182}$ Indeed, subclones sensitive to selection pressure may disappear and be replaced by emerging subclones with innate or acquired resistance. ${ }^{183}$ In particular, eradication of the T790M clone upon osimertinib treatment paves the way for using standard platinum-based chemotherapy or re-introduction of 1 st and 2 nd generation TKIs. ${ }^{184}$ Re-challenging NSCLC that will further progress can even be considered through the re-introduction of osimertinib, provided that the T790M mutation is proven to be back after that 3rd generation TKI has been withdrawn and that other anti-cancer agents have failed. ${ }^{185}$ Consequently, osimertinib administration should be closely bioguided by pharmacogenomic markers - of note, early detection of clonal evolution (i.e. before tumour growth is evidenced upon imaging) allows the initiation of sequential therapies, thus limiting the risk of disease progression and metastasis in patients with lung cancer. ${ }^{186}$

\section{Ibrutinib}

Ibrutinib is an example of a TKI that is registered for treatment of several B-cell malignancies including chronic lymphocytic leukemia (CLL). Ibrutinib is an irreversible Bruton tyrosine kinase (BTK) inhibitor, forming a covalent bond with the cysteine 481 residue in the adenosine triphosphate (ATP)-binding domain of the kinase. ${ }^{187}$ BTK is a cytoplasmic protein involved in $\mathrm{B}$-cell receptor (BCR) signal transduction and is important for antigen-induced $\mathrm{BCR}$ activation in normal developing and mature B cells (Bruton's disease, or X-linked agammaglobulinemia, derives from BTK mutations). BTK activates, among others, phospholipase C- $\gamma 2$ (PLC- $\nu 2$ ) and the NF-KB and NF-AT transcription factor pathways, both being involved in many cellular responses (proliferation, survival, migration/retention). BTK is not mutated but constitutively phosphorylated in B cell lymphoma with chronic BCR activation, such as the autonomous BCR signaling (without antigen) which has been described in CLL cells. ${ }^{188}$ BTK belongs to the TEC family kinases (TFKs), and other members of this family (TEC, ITK, BMX, RLK/TXK) are also targeted by ibrutinib, albeit at higher concentrations. Ibrutinib inhibits other kinases such as BRK and CSJK at similar concentrations to BTK, exhibiting an IC50 for BTK of $0.5 \mathrm{nM} .{ }^{189}$

Monitoring ibrutinib treatment consists of evaluating its efficacy, emergence of resistant clones and side effects. Efficacy evaluation is based on clinical assessment together with CT 
scan (performed every 6 months) to assess the lymph node response. Lymphocytosis is often observed during the first weeks of treatment (peak value after a median time of 4 weeks) and then slowly declines. ${ }^{190}$ Ibrutinib decreases both survival and adhesion of CLL cells within their tumour niches, resulting in rapid redistribution towards the bloodstream, and progressive elimination by elusive mechanisms. Haematological recovery of blood counts (haemoglobinemia, platelets) in patients with pre-existing cytopenia represents an additional biological parameter of ibrutinib efficacy. During clinical development, monitoring BTK occupancy of the subjects' PBMCs before and after treatment was performed using a fluorescent affinity probe; ${ }^{187}$ the results were part of the rationale to choose the standard dose of ibrutinib, but this monitoring is never performed in routine clinical practice.

Early progressions ( $<2$ years) are most often due to transformation of CLL into an aggressive diffuse large B cell lymphoma (aka Richter syndrome), but after 2 years patient relapse is driven by subclones carrying acquired mutations of BTK at the binding site of ibrutinib, or in PLCG2, the protein immediately downstream of BTK. ${ }^{191}$ These mutations were found in $85 \%$ of patients experiencing relapse of CLL and were detected at an estimated median of 9.3 months before relapse. ${ }^{192}$ BTK C481 and PLCG2 mutations are widely used as biomarkers for future relapse during ibrutinib treatment.

As its main side effect, ibrutinib is associated with bleeding in more than half of patients, with events ranging from minor mucocutaneous bleeding to life-threatening haemorrhage. ${ }^{193}$ Ibrutinib inhibits several intracellular proteins important for platelet signalling including BTK and TEC, which are involved in the downstream signalling of the platelet collagen receptor (glycoprotein VI), and C-type lectin-like receptor 2. BTK is also essential in von Willebrand factor (vWF)-induced signalling and GPIb-mediated thrombus formation in vivo. Monitoring bleeding tendency using a quantitative assessment of vWF/ristocetin-induced platelet aggregation (RIPA) in ibrutinib-treated CLL patients has been proposed. However, this assessment is not yet performed routinely. Today, the recommendations regarding this bleeding-risk are limited to contraindication of vitamin $\mathrm{K}$ antagonists and restricted use of other dual antiplatelet therapies. Atrial fibrillation and flutter have been reported to occur in $5-10 \%$ of patients with ibrutinib, ${ }^{194}$ linked with BTK and TEC inhibition in the heart alongside interaction of ibrutinib with other targets such as HER2. This side effect may justify regular blood pressure monitoring since hypertension represents a co-causal risk of atrial fibrillation. 
Lastly, infections should be closely monitored, as fungal and bacterial infection risk is high for the first six months of month treatment, with reducing frequency while patients recover from the immunosuppression characterising florid CLL.

\section{Pembrolizumab}

Pembrolizumab is an immune checkpoint inhibitor directed against the programmed cell death-1 (PD-1) receptor, a negative regulator of T cell activity found on the T cell membrane. Through blockade of PD-1 binding to programmed death ligands 1 and 2 (PD-L1 and PD-L2), expressed on tumour and antigen presenting cells, pembrolizumab potentiates T cell immune responses, including anti-tumour responses. ${ }^{195}$ Pembrolizumab is approved in Europe for the treatment of unresectable/metastatic melanoma, locally advanced/metastatic NSCLC, locally advanced/metastatic urothelial carcinoma and relapsed/refractory Hodgkin lymphoma. ${ }^{195}$

In clinical trials, pembrolizumab demonstrated relatively high response rates, durable responses and improved overall survival. Clinical responses are typically seen at week 12 , but delayed responses may occur and most patients do not experience durable clinical benefit. Toxicity primarily consisting of immune-related adverse events, though often manageable, can be a major issue. ${ }^{195}$ Early identification of patients most likely to respond to pembrolizumab could help avoid unnecessarily prolonged treatments, thus limiting toxicity and healthcare costs, as well as avoid early termination in patients who will eventually experience clinical benefit.

Imaging assessment of treatment efficacy is challenging as it is difficult to differentiate responders from non-responders early on in treatment. Initial transient increase in total tumour size, or even the appearance of new lesions, due to tumour immune infiltration followed by tumour shrinkage, i.e. pseudo-progression, is indeed often observed during pembrolizumab treatment. ${ }^{195}$ Therefore, surrogate prognostic and predictive biomarkers of response and toxicity are needed to guide clinical decisions when imaging is inconclusive.

Several studies have suggested a significant association between PD-L1 expression on tumour and immune cells on biopsies and clinical response. ${ }^{196}$ However, conflicting results arose from different studies showing a lack of or inconclusive correlations between PD-L1 expression in cancer tissues and objective clinical response. ${ }^{196}$ Therefore, PD-L1 expression is not required 
for patient selection except for NSCLC. High pre-treatment levels of circulating soluble PD-L1 (SPD-L1) have recently been associated with increased likelihood of progressive disease in melanoma patients treated by pembrolizumab. After treatment, short-term increase in SPDL1 was correlated with progressive disease and shorter survival, whereas long-term/delayed increase in SPD-L1 (after 5 months of treatment), indirectly reflecting anti-tumour immune responses, translated into a greater likelihood of developing a partial response. ${ }^{197}$ Other studies sought to enlighten the role of tumour infiltrating lymphocytes (CD8+ $T$ cells) negatively regulated by the PD-1/PD-L1 pathway in response to anti-PD-1 agents. Serial biopsies from melanoma patients treated with pembrolizumab revealed that responders had higher densities of PD-1+CD8 T cells in close proximity to PD-L1+ tumour cells at the invasive tumour margin at baseline and displayed greater CD8+ T cell proliferation, tumour infiltration and effector function upon treatment. ${ }^{198}$ More recently, Huang et al ${ }^{199}$ showed in a small cohort of melanoma patients that the ratio of reinvigorated circulating CD8+ T cells to pretreatment tumour burden, rather than the absolute count of CD8+ T cells, is correlated with clinical response. A ratio cut-off value able to segregate patients by outcomes after 6 weeks of therapy is even proposed. ${ }^{199}$ Other circulating biomarkers have been studied as they are more easily sampled than tumour tissues. Firstly, ctDNA detection at baseline and week 8 was shown to be a significant prognostic factor in terms of progression-free survival and overall survival in NSCLC, melanoma and microsatellite-instable colorectal cancer patients treated with pembrolizumab. ${ }^{200}$ In this very small cohort, only patients with undetectable ctDNA levels at week 8 benefited from pembrolizumab treatment, in terms of a marked and lasting response. $^{200}$ Besides, a high mutational burden was correlated with response to pembrolizumab in melanoma and NSCLC patients, likely related to a high load of immunogenic cancer-specific neo-antigens able to induce clonal expansion of CD8+ T cells. ${ }^{195}$, ${ }^{201}$ Secondly, IL-8 serum concentrations were studied as they reflect tumour burden, since IL8 is a pro-tumoural chemokine secreted by tumour tissues. Changes in serum IL- 8 levels could be used to monitor and predict, with high specificity and sensitivity, clinical benefit from pembrolizumab in melanoma and NSCLC patients as early decreases in IL-8 levels (2-4 weeks after treatment initiation) were associated with longer overall survival. ${ }^{202} \mathrm{IL}-8$ concentrations may also be helpful to identify pseudo-progression. ${ }^{202}$ 
Contrary to efficacy, there is currently no predictive biomarker of immune-related toxicity. ${ }^{203}$ So far, serum IL-8 levels have been studied, but no significant association with toxicity was observed. ${ }^{202}$ As previously illustrated for EGFR and VEGFR inhibitors, toxicity can be related to efficacy. In NSCLC patients treated by anti-PD-1 agents, including pembrolizumab, thyroid dysfunction upon treatment was shown to be an independent predictive marker of response, since progression-free survival and overall survival were significantly longer in the thyroid dysfunction group. ${ }^{203}$

Considering the increasingly wide use of anti-PD-1 agents, including pembrolizumab, a major challenge is to identify companion biomarkers of efficacy and toxicity and to assess their medical and economic benefits. While this need still remains unmet, active ongoing research is being carried out in this area. ${ }^{204}$

\section{Summary}

In the current era of targeted anti-cancer drug therapy, where treatment is increasingly driven by stratified medicine approaches, there is clearly scope for the utility of pharmacodynamic biomarkers to support treatment decisions. Indeed, such approaches are likely to be key to the successful development and use of molecularly targeted agents in a cancer setting in terms of selecting the most appropriate drugs and dosing schedules for individual patients (Figure 2). This could potentially involve the use of pharmacodynamic biomarkers to assess response to treatment, incorporating information obtained from relevant surrogate markers of activity as discussed in the current review. While we may not yet be in a position to widely implement TDM approaches based on pharmacodynamic information in a cancer patient setting, such approaches will become more commonplace in the coming years. Based on the wealth of pharmacodynamic information being generated on newer anti-cancer drugs and the various different experimental approaches available to researchers to collect these data, we can now look forward optimistically to significant advances being made in this area. 
Figure Legends

Figure 1. Illustration of a phenomenological pharmacokinetic/pharmacodynamic (PK/PD) modelling approach - 1) basic description of physiological/mechanism of actions of drugs to be combined; 2) translation into mathematical formulae to describe the processes involved; 3) addition of known PK/PD data; 4) computation of the optimal way to combine drugs; 5$)$ validation of the proposed schedule in mice; 6) testing of the optimised model in patients.

Figure 2. Incorporation of pharmacodynamic biomarker therapeutic drug monitoring approaches into the updated pharmacological audit trail (PhAT) proposed and developed by Workman and colleagues. 205,206 


\section{References}

1. Bardin C, Veal G, Paci A, et al. Therapeutic drug monitoring in cancer - are we missing a trick? Eur J Cancer. 2014;50:2005-2009.

2. Gengenbacher N, Singhal M, Augustin HG. Preclinical mouse solid tumour models: status quo, challenges and perspectives. Nat Rev Cancer. 2017;17:751-765.

3. Adjei AA, Cohen RB, Franklin W, et al. Phase I pharmacokinetic and pharmacodynamic study of the oral, small-molecule mitogen-activated protein kinase kinase 1/2 inhibitor AZD6244 (ARRY-142886) in patients with advanced cancers. J Clin Oncol. 2008;26:2139-2146.

4. Linder S. Cytokeratin markers come of age. Tumour Biol. 2007;28:189-195.

5. Biven $\mathrm{K}$, Erdal $\mathrm{H}$, Hagg $\mathrm{M}$, et al. A novel assay for discovery and characterization of pro-apoptotic drugs and for monitoring apoptosis in patient sera. Apoptosis. 2003;8:263-268.

6. Kramer G, Erdal H, Mertens HJ, et al. Differentiation between cell death modes using measurements of different soluble forms of extracellular cytokeratin 18. Cancer Res. 2004;64:1751-1756.

7. Steele NL, Plumb JA, Vidal L, et al. A phase 1 pharmacokinetic and pharmacodynamic study of the histone deacetylase inhibitor belinostat in patients with advanced solid tumors. Clin Cancer Res. 2008;14:804-810.

8. Dive C, Smith RA, Garner E, et al. Considerations for the use of plasma cytokeratin 18 as a biomarker in pancreatic cancer. Br J Cancer. 2010;102:577-582.

9. Dean EJ, Cummings J, Roulston A, et al. Optimization of circulating biomarkers of obatoclax-induced cell death in patients with small cell lung cancer. Neoplasia. 2011;13:339-347.

10. Demiray M, Ulukaya EE, Arslan M, et al. Response to neoadjuvant chemotherapy in breast cancer could be predictable by measuring a novel serum apoptosis product, caspase-cleaved cytokeratin 18: a prospective pilot study. Cancer Invest. 2006;24:669-676.

11. de Haas EC, di Pietro A, Simpson KL, et al. Clinical evaluation of M30 and M65 ELISA cell death assays as circulating biomarkers in a drug-sensitive tumor, testicular cancer. Neoplasia. 2008;10:1041-1048.

12. Scott LC, Evans TR, Cassidy J, et al. Cytokeratin 18 in plasma of patients with gastrointestinal adenocarcinoma as a biomarker of tumour response. $\mathrm{Br} J$ Cancer. 2009;101:410-417. 
13. Drew $\mathrm{Y}$, Ledermann J, Hall G, et al. Phase 2 multicentre trial investigating intermittent and continuous dosing schedules of the poly(ADP-ribose) polymerase inhibitor rucaparib in germline BRCA mutation carriers with advanced ovarian and breast cancer. Br J Cancer. 2016;114:723-730.

14. Kummar S, Chen A, Ji J, et al. Phase I study of PARP inhibitor ABT-888 in combination with topotecan in adults with refractory solid tumors and lymphomas. Cancer Res. 2011;71:5626-5634.

15. Kinders R, Parchment RE, Ji J, et al. Phase 0 clinical trials in cancer drug development: from FDA guidance to clinical practice. Mol Interv. 2007;7:325-334.

16. Donawho CK, Luo Y, Luo Y, et al. ABT-888, an orally active poly(ADP-ribose) polymerase inhibitor that potentiates DNA-damaging agents in preclinical tumor models. Clinical Cancer Res. 2007;13:2728-2737.

17. Ji J, Kinders RJ, Zhang $\mathrm{Y}$, et al. Modeling pharmacodynamic response to the poly(ADPRibose) polymerase inhibitor ABT-888 in human peripheral blood mononuclear cells. PLoS One. 2011;6:e26152.

18. Tunger A, Kiessler M, Wehner R, et al. Immune Monitoring of Cancer Patients Prior to and During CTLA-4 or PD-1/PD-L1 Inhibitor Treatment. Biomedicines. 2018;6.

19. Wolchok JD, Neyns B, Linette $G$, et al. Ipilimumab monotherapy in patients with pretreated advanced melanoma: a randomised, double-blind, multicentre, phase 2, dose-ranging study. Lancet Oncol. 2010;11:155-164.

20. Ku GY, Yuan J, Page DB, et al. Single-institution experience with ipilimumab in advanced melanoma patients in the compassionate use setting: lymphocyte count after 2 doses correlates with survival. Cancer. 2010;116:1767-1775.

21. Delyon J, Mateus C, Lefeuvre D, et al. Experience in daily practice with ipilimumab for the treatment of patients with metastatic melanoma: an early increase in lymphocyte and eosinophil counts is associated with improved survival. Ann Oncol. 2013;24:1697-1703.

22. Berman DM, Wolchok J, Weber J, et al. Association of peripheral blood absolute lymphocyte count (ALC) and clinical activity in patients (pts) with advanced melanoma treated with ipilimumab. J Clin Oncol. 2009;27.

23. Liakou $\mathrm{Cl}$, Kamat $\mathrm{A}$, Tang DN, et al. CTLA-4 blockade increases IFNgamma-producing $\mathrm{CD} 4+\mathrm{ICOShi}$ cells to shift the ratio of effector to regulatory $\mathrm{T}$ cells in cancer patients. Proc Natl Acad Sci USA. 2008;105:14987-14992.

24. Tang DN, Shen Y, Sun J, et al. Increased Frequency of ICOS+ CD4 T Cells as a pharmacodynamic biomarker for anti-CTLA-4 therapy (vol 1, pg 229, 2013). Cancer Immunol Res. 2013;1:501-501. 
25. Romano E, Kusio-Kobialka M, Foukas PG, et al. Ipilimumab-dependent cell-mediated cytotoxicity of regulatory T cells ex vivo by nonclassical monocytes in melanoma patients. Proc Natl Acad Sci USA. 2015;112:6140-6145.

26. Martens A, Wistuba-Hamprecht $K$, Geukes Foppen $M$, et al. Baseline Peripheral Blood Biomarkers Associated with Clinical Outcome of Advanced Melanoma Patients Treated with Ipilimumab. Clin Cancer Res. 2016;22:2908-2918.

27. Wang W, Yu D, Sarnaik AA, et al. Biomarkers on melanoma patient T cells associated with ipilimumab treatment. J Trans/ Med. 2012;10:146.

28. Kamphorst AO, Pillai RN, Yang S, et al. Proliferation of PD-1+CD8 T cells in peripheral blood after PD-1-targeted therapy in lung cancer patients. Proc Natl Acad Sci USA. 2017;114:4993-4998.

29. Phillips RL, Sachs AB. Skin biopsies for the measurement of clinical pharmacodynamic biomarkers. Curr Opin Biotechnol. 2005;16:687-690.

30. Jones PH, Harper S, Watt FM. Stem cell patterning and fate in human epidermis. Cell. 1995;80:83-93.

31. Nanba D, Toki F, Barrandon Y, et al. Recent advances in the epidermal growth factor receptor/ligand system biology on skin homeostasis and keratinocyte stem cell regulation. J Dermatol Sci. 2013;72:81-86.

32. Pollack VA, Savage DM, Baker DA, et al. Inhibition of epidermal growth factor receptor-associated tyrosine phosphorylation in human carcinomas with $\mathrm{CP}-358,774$ : dynamics of receptor inhibition in situ and antitumor effects in athymic mice. $J$ Pharmacol Exp Ther. 1999;291:739-748.

33. Moasser MM, Basso A, Averbuch SD, et al. The tyrosine kinase inhibitor ZD1839 ("Iressa") inhibits HER2-driven signaling and suppresses the growth of HER2overexpressing tumor cells. Cancer Res. 2001;61:7184-7188.

34. Malik SN, Siu LL, Rowinsky EK, et al. Pharmacodynamic evaluation of the epidermal growth factor receptor inhibitor OSI-774 in human epidermis of cancer patients. Clin Cancer Res. 2003;9:2478-2486.

35. Albanell J, Rojo F, Averbuch S, et al. Pharmacodynamic studies of the epidermal growth factor receptor inhibitor ZD1839 in skin from cancer patients: histopathologic and molecular consequences of receptor inhibition. J Clin Oncol. 2002;20:110-124.

36. Baselga J, Rischin D, Ranson M, et al. Phase I safety, pharmacokinetic, and pharmacodynamic trial of ZD1839, a selective oral epidermal growth factor receptor tyrosine kinase inhibitor, in patients with five selected solid tumor types. $J$ Clin Oncol. 2002;20:4292-4302.

37. Ohyama M. Hair follicle bulge: a fascinating reservoir of epithelial stem cells. $J$ Dermatol Sci. 2007;46:81-89. 
38. Camidge DR, Randall KR, Foster JR, et al. Plucked human hair as a tissue in which to assess pharmacodynamic end points during drug development studies. Br J Cancer. 2005;92:1837-1841.

39. Rogakou EP, Pilch DR, Orr AH, et al. DNA double-stranded breaks induce histone H2AX phosphorylation on serine 139. J Biol Chem. 1998;273:5858-5868.

40. Paull TT, Rogakou EP, Yamazaki V, et al. A critical role for histone H2AX in recruitment of repair factors to nuclear foci after DNA damage. Curr Biol. 2000;10:886-895.

41. Williams R, Baker AF, Ihle NT, et al. The skin and hair as surrogate tissues for measuring the target effect of inhibitors of phosphoinositide-3-kinase signaling. Cancer Chemother Pharmacol. 2006;58:444-450.

42. Yap TA, Yan L, Patnaik A, et al. First-in-man clinical trial of the oral pan-AKT inhibitor MK-2206 in patients with advanced solid tumors. J Clin Oncol. 2011;29:4688-4695.

43. Camidge DR, Pemberton M, Growcott J, et al. A phase I pharmacodynamic study of the effects of the cyclin-dependent kinase-inhibitor AZD5438 on cell cycle markers within the buccal mucosa, plucked scalp hairs and peripheral blood mononucleocytes of healthy male volunteers. Cancer Chemother Pharmacol. 2007;60:479-488.

44. Moll I. Differential epithelial outgrowth of plucked and microdissected human hair follicles in explant culture. Arch Dermatol Res. 1996;288:604-610.

45. Parvez K, Parvez A, Zadeh G. The diagnosis and treatment of pseudoprogression, radiation necrosis and brain tumor recurrence. Int J Mol Sci. 2014;15:11832-11846.

46. Sharma S. Tumor markers in clinical practice: General principles and guidelines. Indian J Med Paediatr Oncol. 2009;30:1-8.

47. Bartel DP. MicroRNAs: genomics, biogenesis, mechanism, and function. Cell. 2004;116:281-297.

48. Lu J, Getz G, Miska EA, et al. MicroRNA expression profiles classify human cancers. Nature. 2005;435:834-838.

49. Volinia S, Calin GA, Liu CG, et al. A microRNA expression signature of human solid tumors defines cancer gene targets. Proc Natl Acad Sci USA. 2006;103:2257-2261.

50. Lawrie $\mathrm{CH}, \mathrm{Gal}$ S, Dunlop HM, et al. Detection of elevated levels of tumourassociated microRNAs in serum of patients with diffuse large B-cell lymphoma. Br J Haematol. 2008;141:672-675.

51. Ali S, Almhanna K, Chen W, et al. Differentially expressed miRNAs in the plasma may provide a molecular signature for aggressive pancreatic cancer. Am J Transl Res. 2010;3:28-47. 
52. Cui EH, Li HJ, Hua F, et al. Serum microRNA $125 \mathrm{~b}$ as a diagnostic or prognostic biomarker for advanced NSCLC patients receiving cisplatin-based chemotherapy. Acta Pharmacologica Sinica. 2013;34:309-313.

53. Tanaka K, Miyata $\mathrm{H}$, Yamasaki $\mathrm{M}$, et al. Circulating miR-200c levels significantly predict response to chemotherapy and prognosis of patients undergoing neoadjuvant chemotherapy for esophageal cancer. Ann Surg Oncol. 2013;20 Suppl 3:S607-615.

54. Greystoke A, Ayub M, Rothwell DG, et al. Development of a circulating miRNA assay to monitor tumor burden: From mouse to man. Mol Oncol. 2016;10:282-291.

55. Antoine DJ, Dear JW, Lewis PS, et al. Mechanistic biomarkers provide early and sensitive detection of acetaminophen-induced acute liver injury at first presentation to hospital. Hepatology. 2013;58:777-787.

56. National Institutes of Health ClinicalTrials.gov website.

https://clinicaltrials.gov/ct2/show/NCT03039062. Published February 01, 2017. Accessed August 30, 2018.

57. Zhao Z, He J, Zhang J, et al. Dysregulated miR1254 and miR579 for cardiotoxicity in patients treated with bevacizumab in colorectal cancer. Tumour Biol. 2014;35:52275235.

58. Krebs MG, Hou JM, Ward TH, et al. Circulating tumour cells: their utility in cancer management and predicting outcomes. Ther Adv Med Oncol. 2010;2:351-365.

59. Yap TA, Lorente D, Omlin A, et al. Circulating tumor cells: a multifunctional biomarker. Clin Cancer Res. 2014;20:2553-2568.

60. Allard WJ, Matera J, Miller MC, et al. Tumor cells circulate in the peripheral blood of all major carcinomas but not in healthy subjects or patients with nonmalignant diseases. Clin Cancer Res. 2004;10:6897-6904.

61. Cristofanilli M, Budd GT, Ellis MJ, et al. Circulating tumor cells, disease progression, and survival in metastatic breast cancer. New Engl J Med. 2004;351:781-791.

62. Hayes DF, Cristofanilli M, Budd GT, et al. Circulating tumor cells at each follow-up time point during therapy of metastatic breast cancer patients predict progressionfree and overall survival. Clin Cancer Res. 2006;12:4218-4224.

63. de Bono JS, Scher HI, Montgomery RB, et al. Circulating tumor cells predict survival benefit from treatment in metastatic castration-resistant prostate cancer. Clin Cancer Res. 2008;14:6302-6309.

64. Cohen SJ, Punt CJ, lannotti N, et al. Relationship of circulating tumor cells to tumor response, progression-free survival, and overall survival in patients with metastatic colorectal cancer. J Clin Oncol. 2008;26:3213-3221. 
65. Ogle LF, Orr JG, Willoughby CE, et al. Imagestream detection and characterisation of circulating tumour cells - A liquid biopsy for hepatocellular carcinoma? J Hepatol. 2016;65:305-313.

66. Chudziak J, Burt DJ, Mohan S, et al. Clinical evaluation of a novel microfluidic device for epitope-independent enrichment of circulating tumour cells in patients with small cell lung cancer. Analyst. 2016;141:669-678.

67. Maheswaran S, Sequist LV, Nagrath S, et al. Detection of mutations in EGFR in circulating lung-cancer cells. New Engl J Med. 2008;359:366-377.

68. Jahr S, Hentze H, Englisch S, et al. DNA fragments in the blood plasma of cancer patients: quantitations and evidence for their origin from apoptotic and necrotic cells. Cancer Res. 2001;61:1659-1665.

69. Kahlert C, Melo SA, Protopopov A, et al. Identification of double-stranded genomic DNA spanning all chromosomes with mutated KRAS and p53 DNA in the serum exosomes of patients with pancreatic cancer. J Biol Chem. 2014;289:3869-3875.

70. Beaver JA, Jelovac D, Balukrishna S, et al. Detection of cancer DNA in plasma of patients with early-stage breast cancer. Clin Cancer Res. 2014;20:2643-2650.

71. Forshew T, Murtaza M, Parkinson $\mathrm{C}$, et al. Noninvasive identification and monitoring of cancer mutations by targeted deep sequencing of plasma DNA. Sci Transl Med. 2012;4:136ra168.

72. Leary RJ, Sausen M, Kinde I, et al. Detection of chromosomal alterations in the circulation of cancer patients with whole-genome sequencing. Sci Transl Med. 2012;4:162ra154.

73. Chan KC, Jiang $P$, Zheng YW, et al. Cancer genome scanning in plasma: detection of tumor-associated copy number aberrations, single-nucleotide variants, and tumoral heterogeneity by massively parallel sequencing. Clin Chem. 2013;59:211-224.

74. Heitzer E, Auer M, Hoffmann EM, et al. Establishment of tumor-specific copy number alterations from plasma DNA of patients with cancer. Int J Cancer. 2013;133:346356.

75. Diaz LA, Jr., Williams RT, Wu J, et al. The molecular evolution of acquired resistance to targeted EGFR blockade in colorectal cancers. Nature. 2012;486:537-540.

76. Dawson SJ, Tsui DW, Murtaza M, et al. Analysis of circulating tumor DNA to monitor metastatic breast cancer. New Engl J Med. 2013;368:1199-1209.

77. Saumet A, Lecellier $\mathrm{CH}$. microRNAs and Personalized Medicine: Evaluating Their Potential as Cancer Biomarkers. Adv Exp Med Biol. 2015;888:5-15.

78. Wang Y, Probin V, Zhou D. Cancer therapy-induced residual bone marrow injuryMechanisms of induction and implication for therapy. Curr Cancer Ther Rev. 2006;2:271-279. 
79. Brana I, Tabernero J. Cardiotoxicity. Annals of Oncology. 2010;21:vii173-vii179.

80. Schindler M, Spycher BD, Ammann RA, et al. Cause-specific long-term mortality in survivors of childhood cancer in Switzerland: A population-based study. Int I Cancer. 2016;139:322-333.

81. Patnaik JL, Byers T, DiGuiseppi C, et al. Cardiovascular disease competes with breast cancer as the leading cause of death for older females diagnosed with breast cancer: a retrospective cohort study. Breast Cancer Res. 2011;13:R64.

82. Armstrong GT, Liu Q, Yasui Y, et al. Late mortality among 5-year survivors of childhood cancer: a summary from the Childhood Cancer Survivor Study. J Clin Oncol. 2009;27:2328-2338.

83. Vejpongsa P, Yeh ETH. Prevention of anthracycline-induced cardiotoxicity: challenges and opportunities. J Am Coll Cardiol. 2014;64:938-945.

84. Sawyer DB, Peng X, Chen B, et al. Mechanisms of anthracycline cardiac injury: can we identify strategies for cardioprotection? Prog Cardiovasc Dis. 2010;53:105-113.

85. Cote GM, Sawyer DB, Chabner BA. ERBB2 Inhibition and Heart Failure. New Engl J Med. 2012;367:2150-2153.

86. Suter TM, Procter M, van Veldhuisen DJ, et al. Trastuzumab-associated cardiac adverse effects in the herceptin adjuvant trial. J Clin Oncol. 2007;25:3859-3865.

87. Summary of Product Characteristics Trastuzumab.

https://www.nice.org.uk/guidance/ta107/documents/summary-of-productcharacteristics2. Accessed August 30, 2018.

88. van Hasselt JGC, Schellens JHM, Mac Gillavry MR, et al. Model-based evaluation and optimization of cardiac monitoring protocols for adjuvant treatment of breast cancer with trastuzumab. Pharm Res. 2012;29:3499-3511.

89. Swain SM, Whaley FS, Ewer MS. Congestive heart failure in patients treated with doxorubicin: a retrospective analysis of three trials. Cancer. 2003;97:2869-2879.

90. Conte PF, Gennari A, Landucci E, et al. Role of epirubicin in advanced breast cancer. Clin Breast Cancer. 2000;1 Suppl 1:S46-51.

91. Farah CS, Reinach FC. The troponin complex and regulation of muscle contraction. FASEB J. 1995;9:755-767.

92. Maisel A. Biomonitoring and biomarker-guided therapy: the next step in heart failure and biomarker research. J Am Coll Cardiol. 2011;58:1890-1892.

93. Ponikowski P, Voors AA, Anker SD, et al. 2016 ESC Guidelines for the diagnosis and treatment of acute and chronic heart failure: The Task Force for the diagnosis and treatment of acute and chronic heart failure of the European Society of Cardiology 
(ESC)Developed with the special contribution of the Heart Failure Association (HFA) of the ESC. Eur Heart J. 2016;37:2129-2200.

94. Ibanez B, James S, Agewall S, et al. 2017 ESC Guidelines for the management of acute myocardial infarction in patients presenting with ST-segment elevation: The Task Force for the management of acute myocardial infarction in patients presenting with ST-segment elevation of the European Society of Cardiology (ESC). Eur Heart J. 2018;39:119-177.

95. Fu S, Ping $P$, Wang $F$, et al. Synthesis, secretion, function, metabolism and application of natriuretic peptides in heart failure. J Biol Eng. 2018;12:2.

96. Cardinale D, Sandri MT, Colombo A, et al. Prognostic value of troponin I in cardiac risk stratification of cancer patients undergoing high-dose chemotherapy. Circulation. 2004;109:2749-2754.

97. Zardavas D, Suter TM, Van Veldhuisen DJ, et al. Role of Troponins I and T and NTerminal Prohormone of Brain Natriuretic Peptide in Monitoring Cardiac Safety of Patients With Early-Stage Human Epidermal Growth Factor Receptor 2-Positive Breast Cancer Receiving Trastuzumab: A Herceptin Adjuvant Study Cardiac Marker Substudy. J Clin Oncol. 2017;35:878-884.

98. de Vries Schultink AHM, Boekhout AH, Gietema JA, et al. Pharmacodynamic modeling of cardiac biomarkers in breast cancer patients treated with anthracycline and trastuzumab regimens. J Pharmacokinet Pharmacodyn. 2018;45:431-442.

99. Cardinale D, Colombo A, Bacchiani G, et al. Early detection of anthracycline cardiotoxicity and improvement with heart failure therapy. Circulation. 2015;131:1981-1988.

100. National Institutes of Health ClinicalTrials.gov website.

https://clinicaltrials.gov/ct2/show/NCT01032278. Published December 25, 2009. Accessed August 30, 2018.

101. National Institutes of Health ClinicalTrials.gov website. https://clinicaltrials.gov/ct2/show/NCT03155802. Published May 16, 2017. Accessed August 30, 2018.

102. Ranpura V, Pulipati,B, Chu D, et al. Increased Risk of High-Grade Hypertension With Bevacizumab in Cancer Patients: A Meta-Analysis. Am J Hypertens. 2010;23:460-468.

103. Wu S, Chen JJ, Kudelka A, et al. Incidence and risk of hypertension with sorafenib in patients with cancer: a systematic review and meta-analysis. Lancet Oncol. 2008;9:117-123.

104. Zhu X, Stergiopoulos K, Wu S. Risk of hypertension and renal dysfunction with an angiogenesis inhibitor sunitinib: systematic review and meta-analysis. Acta Oncol. 2009;48:9-17. 
105. Scartozzi M, Galizia E, Chiorrini S, et al. Arterial hypertension correlates with clinical outcome in colorectal cancer patients treated with first-line bevacizumab. Ann Oncol. 2008;20:227-230.

106. Yeh ETH, Bickford CL. Cardiovascular complications of cancer therapy. J Am Coll Cardiol. 2009;53:2231-2247.

107. Suter TM, Ewer MS. Cancer drugs and the heart: importance and management. Eur Heart J. 2013;34:1102-1111.

108. Rini BI, Cohen DP, Lu DR, et al. Hypertension as a biomarker of efficacy in patients with metastatic renal cell carcinoma treated with sunitinib. J Natl Cancer Inst. 2011;103:763-773.

109. George S, Reichardt P, Lechner T, et al. Hypertension as a potential biomarker of efficacy in patients with gastrointestinal stromal tumor treated with sunitinib. Ann Oncol. 2012;23:3180-3187.

110. Murukesh N, Dive C, Jayson GC. Biomarkers of angiogenesis and their role in the development of VEGF inhibitors. Br J Cancer. 2010;102:8-18.

111. Pant S, Martin LK, Geyer S, et al. Treatment-related hypertension as a pharmacodynamic biomarker for the efficacy of bevacizumab in advanced pancreas cancer: a pooled analysis of 4 prospective trials of gemcitabine-based therapy with bevacizumab. Am J Clin Oncol. 2016;39:614-618.

112. Strumberg D, Brügge $\mathrm{S}$, Korn MW, et al. Evaluation of long-term toxicity in patients after cisplatin-based chemotherapy for non-seminomatous testicular cancer. Ann Oncol. 2002;13:229-236.

113. Crona DJ, Faso A, Nishijima TF, et al. A systematic review of strategies to prevent cisplatin-induced nephrotoxicity. The Oncologist. 2017:22;609-619.

114. Soultati A, Mountzios G, Avgerinou, et al. Endothelial vascular toxicity from chemotherapeutic agents: Preclinical evidence and clinical implications. Cancer Treat Rev. 2012;38:473-483.

115. Vaidya VS, Ferguson MA, Bonventre JV. Biomarkers of acute kidney injury. Annu Rev Pharmacol Toxicol. 2008;48:463-493.

116. George B, Joy MS, Aleksunes LM. Urinary protein biomarkers of kidney injury in patients receiving cisplatin chemotherapy. Exp Biol Med. 2018;243:272-282.

117. Meinardi MT, Gietema JA, van der Graaf WT, et al. Cardiovascular morbidity in longterm survivors of metastatic testicular cancer. J Clin Oncol. 2000;18:1725-1732.

118. Ahmadieh $\mathrm{H}$, Salti I. Tyrosine kinase inhibitors induced thyroid dysfunction: a review of its incidence, pathophysiology, clinical relevance, and treatment. BioMed Res Int. 2013;2013:725410. 
119. Hamnvik OP, Larsen PR, Marqusee E. Thyroid dysfunction from antineoplastic agents. J Natl Cancer Inst. 2011;103:1572-1587.

120. Desai J, Yassa L, Marqusee E. Hypothyroidism after sunitinib treatment for patients with gastrointestinal stromal tumors. Ann Intern Med. 2006;145:660-664.

121. Rini BI, Tamaskar I, Shaheen P, et al. Hypothyroidism in patients with metastatic renal cell carcinoma treated with sunitinib. J Natl Cancer Inst. 2007;99:81-83.

122. Wolter P, Stefan C, Decallonne B, et al. The clinical implications of sunitinib-induced hypothyroidism: a prospective evaluation. Br J Cancer. 2008;99:448-454.

123. Mannavola D, Coco P, Vannucchi G, et al. A novel tyrosine-kinase selective inhibitor, sunitinib, induces transient hypothyroidism by blocking iodine uptake. J Clin Endocrinol Metab. 2007;92:3531-3534.

124. Garfield D, Hercbergs A, Davis P. Unanswered questions regarding the management of sunitinib-induced hypothyroidism. Nat Clin Pract Oncol. 2007;4:674.

125. O'Connor P, Feely J. Clinical pharmacokinetics and endocrine disorders. Therapeutic implications. Clin Pharmacokinet. 1987;13:345-364.

126. Ueno T, Toi M, Linder S. Detection of epithelial cell death in the body by cytokeratin 18 measurement. Biomed Pharmacother. 2005;59 Suppl 2:S359-362.

127. Kramer G, Erdal H, Mertens HJMM, et al. Differentiation between Cell Death Modes Using Measurements of Different Soluble Forms of Extracellular Cytokeratin 18. Cancer Res. 2004;64:1751-1756.

128. Oyama K, Fushida S, Kinoshita J, et al. Serum cytokeratin 18 as a biomarker for gastric cancer. Clin Exp Med. 2013;13:289-295.

129. Greystoke A, Dean E, Saunders MP, et al. Multi-level evidence that circulating CK18 is a biomarker of tumour burden in colorectal cancer. Br J Cancer. 2012;107:15181524.

130. Sen F, Yildiz I, Odabas $\mathrm{H}$, et al. Diagnostic value of serum M30 and M65 in patients with nasopharyngeal carcinoma. Tumour Biol. 2015;36:1039-1044.

131. Chu T, Jiang L, Ying $\mathrm{W}$, et al. M30/M65 ratio predicts the outcome of paclitaxel chemotherapy for NSCLC. Clin Transl Oncol. 2017;19:326-331.

132. Greystoke A, O'Connor JPB, Linton K, et al. Assessment of circulating biomarkers for potential pharmacodynamic utility in patients with lymphoma. Br J Cancer. 2011;104:719-725.

133. Eguchi A, Wree A, Feldstein AE. Biomarkers of liver cell death. J Hepatol. 2014;60:1063-1074.

134. Kozuki T. Skin problems and EGFR-tyrosine kinase inhibitor. Jpn J Clin Oncol. 2016;46:291-298. 
135. Belum VR, Fischer A, Choi JN, et al. Dermatological adverse events from BRAF inhibitors: a growing problem. Curr Oncol Rep. 2013;15:249-259.

136. Lupu I, Voiculescu VM, Bacalbasa N. Cutaneous adverse reactions specific to epidermal growth factor receptor inhibitors. J Med Life. 2015;8:57-61.

137. Gençler B, Gönül M. Cutaneous side effects of BRAF inhibitors in advanced melanoma: review of the literature. Dermatol Res Pract. 2016;2016:5361569.

138. Soulieres D, Senzer NN, Vokes EE, et al. Multicenter phase II study of erlotinib, an oral epidermal growth factor receptor tyrosine kinase inhibitor, in patients with recurrent or metastatic squamous cell cancer of the head and neck. J Clin Oncol. 2004;22:77-85.

139. Gordon AN, Finkler N, Edwards RP, et al. Efficacy and safety of erlotinib $\mathrm{HCl}$, an epidermal growth factor receptor (HER1/EGFR) tyrosine kinase inhibitor, in patients with advanced ovarian carcinoma: results from a phase II multicenter study. Int J Gynecol Cancer. 2005;15:785-792.

140. Pérez-Soler R, Chachoua A, Hammond LA, et al. Determinants of tumor response and survival with erlotinib in patients with non-small-cell lung cancer. J Clin Oncol. 2004;22:3238-3247.

141. Mitsudomi T, Morita S, Yatabe Y, et al. Gefitinib versus cisplatin plus docetaxel in patients with non-small-cell lung cancer harbouring mutations of the epidermal growth factor receptor (WJTOG3405): an open label, randomised phase 3 trial. Lancet Oncol. 2010;11:121-128.

142. Urata $\mathrm{Y}$, Katakami N, Morita S, et al. Randomized phase III study comparing gefitinib with erlotinib in patients with previously treated advanced lung adenocarcinoma: WJOG 5108L. J Clin Oncol. 2016;34:3248-3257.

143. Mok TS, Wu Y-L, Thongprasert S, et al. Gefitinib or carboplatin-paclitaxel in pulmonary adenocarcinoma. N Engl J Med. 2009;361:947-957.

144. Anforth R, Carlos G, Clements A, et al. Cutaneous adverse events in patients treated with BRAF inhibitor-based therapies for metastatic melanoma for longer than 52 weeks. Br J Dermatol. 2015;172:239-243.

145. Balagula Y, Barth Huston K, Busam KJ, et al. Dermatologic side effects associated with the MEK 1/2 inhibitor selumetinib (AZD6244, ARRY-142886). Invest New Drugs. 2011;29:1114-1121.

146. Jost $M$, Kari C, Rodeck U. The EGF receptor - an essential regulator of multiple epidermal functions. Eur J Dermatol. 2000;10:505-510.

147. Surguladze D, Deevi D, Claros N, et al. Tumor necrosis factor-alpha and interleukin-1 antagonists alleviate inflammatory skin changes associated with epidermal growth factor receptor antibody therapy in mice. Cancer Res. 2009;69:5643-5647. 
148. Wacker B, Nagrani T, Weinberg J, et al. Correlation between development of rash and efficacy in patients treated with the epidermal growth factor receptor tyrosine kinase inhibitor erlotinib in two large phase III studies. Clin Cancer Res.

2007;13:3913-3921.

149. Ding K, Pater J, Whitehead M, et al. Validation of treatment induced specific adverse effect as a predictor of treatment benefit: A case study of NCIC CTG BR21. Contemp Clin Trials. 2008;29:527-536.

150. Bonner JA, Harari PM, Giralt J, et al. Radiotherapy plus cetuximab for locoregionally advanced head and neck cancer: 5-year survival data from a phase 3 randomised trial, and relation between cetuximab-induced rash and survival. Lancet Oncol. 2010;11:21-28.

151. Shah DR, Shah RR, Morganroth J. Tyrosine kinase inhibitors: their on-target toxicities as potential indicators of efficacy. Drug Saf. 2013;36:413-426.

152. Azan A, Caspers PJ, Bakker Schut TC, et al. A novel spectroscopically determined pharmacodynamic biomarker for skin toxicity in cancer patients treated with targeted agents. Cancer Res. 2017;77:557-565.

153. Atkinson BJ, Kalra S, Wang X, et al. Clinical outcomes for patients with metastatic renal cell carcinoma treated with alternative sunitinib schedules. $J$ Urol. 2014;191:611-618.

154. Garland J. Unravelling the complexity of signalling networks in cancer: A review of the increasing role for computational modelling. Crit Rev Oncol Hematol. 2017;117:73-113.

155. Barbolosi D, Ciccolini J, Lacarelle B, et al. Computational oncology--mathematical modelling of drug regimens for precision medicine. Nat Rev Clin Oncol. 2016;13:242254.

156. Stamatakos G, Dionysiou D, Lunzer A, et al. The technologically integrated oncosimulator: combining multiscale cancer modeling with information technology in the in silico oncology context. IEEE J Biomed Health Inform. 2014;18:840-854.

157. Fornari C, O'Connor LO, Yates JWT, et al. Understanding hematological toxicities using mathematical modeling. Clin Pharm Ther. 2018 doi: 10.1002/cpt.1080

158. Iliadis A, Barbolosi D. Optimizing drug regimens in cancer chemotherapy by an efficacy-toxicity mathematical model. Comput Biomed Res. 2000;33:211-226.

159. Vainas O, Ariad S, Amir O, et al. Personalising docetaxel and G-CSF schedules in cancer patients by a clinically validated computational model. $\mathrm{Br} J$ Cancer. 2012;107:814-822.

160. Barbolosi D, Iliadis A. Optimizing drug regimens in cancer chemotherapy: a simulation study using a PK-PD model. Comput Biol Med. 2001;31:157-172. 
161. Meille C, Iliadis A, Barbolosi D, et al. An interface model for dosage adjustment connects hematotoxicity to pharmacokinetics. J Pharmacokinet Pharmacodyn. 2008;35:619-633.

162. Karlsson MO, Port RE, Ratain MJ, et al. A population model for the leukopenic effect of etoposide. Clin Pharm Ther. 1995;57:325-334.

163. Friberg LE, Henningsson A, Maas $\mathrm{H}$, et al. Model of chemotherapy-induced myelosuppression with parameter consistency across drugs. J Clin Oncol. 2002;20:4713-4721.

164. Schmitt A, Gladieff L, Laffont CM, et al. Factors for hematopoietic toxicity of carboplatin: refining the targeting of carboplatin systemic exposure. J Clin Oncol. 2010;28:4568-4574.

165. Ciccolini J, Barbolosi D, Meille C, et al. Pharmacokinetics and PharmacodynamicsBased Mathematical Modeling Identifies an Optimal Protocol for Metronomic Chemotherapy. Cancer Res. 2017;77:4723-4733.

166. Stein $\mathrm{S}$, Zhao $\mathrm{R}$, Haeno $\mathrm{H}$, et al. Mathematical modeling identifies optimum lapatinib dosing schedules for the treatment of glioblastoma patients. PLoS Comput Biol. 2018;14:e1005924.

167. Jain RK. Normalization of tumor vasculature: an emerging concept in antiangiogenic therapy. Science. 2005;307:58-62.

168. Mollard S, Ciccolini J, Imbs DC, et al. Model driven optimization of antiangiogenics + cytotoxics combination: application to breast cancer mice treated with bevacizumab + paclitaxel doublet leads to reduced tumor growth and fewer metastasis. Oncotarget. 2017;8:23087-23098.

169. Imbs DC, El Cheikh R, Boyer A, et al. Revisiting bevacizumab + cytotoxics scheduling using mathematical modeling: proof of concept study in experimental non-small cell lung carcinoma. CPT Pharmacometrics Syst Pharmacol. 2018;7:42-50.

170. Panetta JC, Schaiquevich P, Santana VM, et al. Using pharmacokinetic and pharmacodynamic modeling and simulation to evaluate importance of schedule in topotecan therapy for pediatric neuroblastoma. Clin Cancer Res. 2008;14:318-325.

171. Santana VM, Zamboni WC, Kirstein NM, et al. A pilot study of protracted topotecan dosing using a pharmacokinetically guided dosing approach in children with solid tumors. Clin Cancer Res. 2003;9:633-640.

172. Yu HA, Sima C, Feldman D, et al. Phase 1 study of twice weekly pulse dose and daily low-dose erlotinib as initial treatment for patients with EGFR-mutant lung cancers. Ann Oncol. 2017;28:278-284.

173. Henin E, Meille C, Barbolosi D, et al. Revisiting dosing regimen using PK/PD modeling: the MODEL1 phase I/II trial of docetaxel plus epirubicin in metastatic breast cancer patients. Breast Cancer Res Treat. 2016;156:331-341. 
174. Meille C, Barbolosi D, Ciccolini J, et al. Revisiting dosing regimen using pharmacokinetic/pharmacodynamics mathematical modelling: densification and intensification of combination cancer therapy. Clin Pharmacokinet. 2016;55:10151025.

175. Barbolosi D, Ciccolini J, Meille C, et al. Metronomics chemotherapy: time for computational decision support. Cancer Chemother Pharmacol. 2014;74:647-652.

176. Barlesi F, Imbs DC, Tomasini P, et al. Mathematical modeling for Phase I cancer trials: A study of metronomic vinorelbine for advanced non-small cell lung cancer (NSCLC) and mesothelioma patients. Oncotarget. 2017;8:47161-47166.

177. Paez JG, Janne PA, Lee JC, et al. EGFR mutations in lung cancer: correlation with clinical response to gefitinib therapy. Science. 2004;304:1497-1500.

178. Cross DA, Ashton SE, Ghiorghiu S, et al. AZD9291, an irreversible EGFR TKI, overcomes T790M-mediated resistance to EGFR inhibitors in lung cancer. Cancer Discov. 2014;4:1046-1061.

179. Brown K, Comisar C, Witjes H, et al. Population pharmacokinetics and exposureresponse of osimertinib in patients with non-small cell lung cancer. $\mathrm{Br} \mathrm{J}$ Clin Pharmacol. 2017;83:1216-1226.

180. Gao X, Le X, Costa DB. The safety and efficacy of osimertinib for the treatment of EGFR T790M mutation positive non-small-cell lung cancer. Expert Rev Anticancer Ther. 2016;16:383-390.

181. Knebel FH, Bettoni F, Shimada AK, et al. Sequential liquid biopsies reveal dynamic alterations of EGFR driver mutations and indicate EGFR amplification as a new mechanism of resistance to osimertinib in NSCLC. Lung Cancer. 2017;108:238-241.

182. Ricordel C, Friboulet L, Facchinetti F, et al. Molecular mechanisms of acquired resistance to third-generation EGFR-TKIs in EGFR T790M-mutant lung cancer. Ann Oncol. 2018;29:i28-i37.

183. Heydt C, Michels S, Thress KS, et al. Novel approaches against epidermal growth factor receptor tyrosine kinase inhibitor resistance. Oncotarget. 2018;9:1541815434.

184. Noda S, Kanda S. Addressing epidermal growth factor receptor tyrosine kinase inhibitor resistance in non-small cell lung cancer. Expert Rev Respir Med. 2016;10:547-556.

185. Remon J, Steuer CE, Ramalingam SS, et al. Osimertinib and other third-generation EGFR TKI in EGFR-mutant NSCLC patients. Ann Oncol. 2018;29:i20-i27.

186. Piotrowska Z, Niederst MJ, Karlovich CA, et al. Heterogeneity Underlies the Emergence of EGFRT790 Wild-Type Clones Following Treatment of T790M-Positive Cancers with a Third-Generation EGFR Inhibitor. Cancer Discov. 2015;5:713-722. 
187. Imbruvica package insert, Janssen Biotech Inc.

https://www.janssenmd.com/pdf/imbruvica/imbruvica_pi.pdf. Accessed August 30, 2018.

188. Woyach JA, Bojnik E, Ruppert AS, et al. Bruton's tyrosine kinase (BTK) function is important to the development and expansion of chronic lymphocytic leukemia (CLL). Blood. 2014;123:1207-1213.

189. Honigberg LA, Smith AM, Sirisawad M, et al. The Bruton tyrosine kinase inhibitor PCl32765 blocks $B$-cell activation and is efficacious in models of autoimmune disease and B-cell malignancy. Proc Natl Acad Sci USA. 2010;107:13075-13080.

190. Cheson BD, Fisher RI, Barrington SF, et al. Recommendations for initial evaluation, staging, and response assessment of Hodgkin and non-Hodgkin lymphoma: the Lugano classification. J Clin Oncol. 2014;32:3059-3068.

191. Maddocks KJ, Ruppert AS, Lozanski G, et al. Etiology of ibrutinib therapy discontinuation and outcomes in patients with chronic lymphocytic leukemia. JAMA Oncol. 2015;1:80-87.

192. Woyach JA, Ruppert AS, Guinn D, et al. BTK(C481S)-mediated resistance to ibrutinib in chronic lymphocytic leukemia. J Clin Oncol. 2017;35:1437-1443.

193. Winqvist M, Asklid A, Andersson PO, et al. Real-world results of ibrutinib in patients with relapsed or refractory chronic lymphocytic leukemia: data from 95 consecutive patients treated in a compassionate use program. A study from the Swedish Chronic Lymphocytic Leukemia Group. Haematologica. 2016;101:1573-1580.

194. McMullen JR, Boey EJ, Ooi JY, et al. Ibrutinib increases the risk of atrial fibrillation, potentially through inhibition of cardiac PI3K-Akt signaling. Blood. 2014;124:38293830.

195. Summary of Product Characteristics Pembrolizumab.

http://www.ema.europa.eu/docs/en_GB/document_library/EPAR__Product_Information/human/003820/WC500190990.pdf. Accessed August 30, 2018.

196. Choudhury N, Nakamura Y. Importance of immunopharmacogenomics in cancer treatment: Patient selection and monitoring for immune checkpoint antibodies. Cancer Sci. 2016;107:107-115.

197. Zhou J, Mahoney KM, Giobbie-Hurder A, et al. Soluble PD-L1 as a Biomarker in Malignant Melanoma Treated with Checkpoint Blockade. Cancer Immunol Res. 2017;5:480-492.

198. Tumeh PC, Harview CL, Yearley JH, et al. PD-1 blockade induces responses by inhibiting adaptive immune resistance. Nature. 2014;515:568-571. 
199. Huang AC, Postow MA, Orlowski RJ, et al. T-cell invigoration to tumour burden ratio associated with anti-PD-1 response. Nature. 2017;545:60-65.

200. Cabel L, Riva F, Servois V, et al. Circulating tumor DNA changes for early monitoring of anti-PD1 immunotherapy: a proof-of-concept study. Ann Oncol. 2017;28:19962001.

201. Cogdill AP, Andrews MC, Wargo JA. Hallmarks of response to immune checkpoint blockade. Br J Cancer. 2017;117:1-7.

202. Sanmamed MF, Perez-Gracia JL, Schalper KA, et al. Changes in serum interleukin-8 (IL-8) levels reflect and predict response to anti-PD-1 treatment in melanoma and non-small-cell lung cancer patients. Ann Oncol. 2017;28:1988-1995.

203. Sosa A, Lopez Cadena E, Simon Olive C, et al. Clinical assessment of immune-related adverse events. Ther Adv Med Oncol. 2018;10:1758835918764628.

204. Buder-Bakhaya K, Hassel JC. Biomarkers for clinical benefit of immune checkpoint inhibitor treatment - a review from the melanoma perspective and beyond. Front Immunol. 2018;9:1474

205. Workman P. How much gets there and what does it do?: The need for better pharmacokinetic and pharmacodynamic endpoints in contemporary drug discovery and development. Current Pharm Des. 2003;9:891-902.

206. Yap TA, Sandhu SK, Workman P, et al. Envisioning the future of early anticancer drug development. Nat Rev Cancer. 2010;10:514-523. 
Table 1. Summary of the advantages and disadvantages of different sample types for pharmacodynamic biomarker studies

\begin{tabular}{|c|c|c|c|}
\hline Sample Type & $\begin{array}{c}\text { Ease of } \\
\text { collection }\end{array}$ & Advantages & Disadvantages \\
\hline Tumour biopsy & + & $\begin{array}{l}\text { - Allows assessment of PK/PD relationships at the } \\
\text { site of disease. } \\
\text { - Physiological relevance: Enables the study of } \\
\text { biomarkers that reflect interactions between } \\
\text { different components of the tumour } \\
\text { microenvironment (tumour cells, immune cells, } \\
\text { tumour vasculature and non-malignant cells). }\end{array}$ & $\begin{array}{l}\text { - Requires specialist clinical expertise for sample } \\
\text { collection. } \\
\text { - Invasive and potentially risky procedure. } \\
\text { - Some patients may not be eligible. } \\
\text { the appropriate timepoints pre/post drug } \\
\text { treatment, may not be feasible. } \\
\text { - Limited amount of tumour may be present in core } \\
\text { biopsies, restricting the scope of biomarker analysis. } \\
\text { - Variance due to tissue heterogeneity. } \\
\end{array}$ \\
\hline $\begin{array}{l}\text { Blood (serum, } \\
\text { plasma, } \\
\text { PBMCs) }\end{array}$ & ++ & $\begin{array}{l}\text { - Multiple samples can be taken across the course } \\
\text { of treatment and readily stored for downstream } \\
\text { analysis. } \\
\text { - Highly amenable for the development of routine } \\
\text { clinical assays. } \\
\text { - Samples from healthy volunteers can be readily } \\
\text { obtained for analytical validation of biomarker } \\
\text { assays. }\end{array}$ & $\begin{array}{l}\text { - Consists of predominantly differentiated cell types. } \\
\text { The underlying pathways and mechanisms of drug } \\
\text { action in tumour cells may not be present in blood. } \\
\text { - The characteristics of PBMCs isolated from blood } \\
\text { can differ significantly from immune cells within the } \\
\text { tumour microenvironment } \\
\text { - PK/PD relationships developed by analysis of blood } \\
\text { markers may not extrapolate to tumour tissue. } \\
\text { - Soluble biomarkers may be present in very low } \\
\text { quantities, requiring sensitive and often expensive } \\
\text { methods of detection. }\end{array}$ \\
\hline Skin & + & $\begin{array}{l}\text { - Self-renewing stem cells within skin exhibit } \\
\text { signalling pathways that are involved in cancer cell } \\
\text { function/anti-cancer drug mechanism of action. }\end{array}$ & $\begin{array}{l}\text { Requires specialist clinical expertise for sample } \\
\text { collection. } \\
\text { - Invasive procedure therefore multiple sampling may } \\
\text { not be acceptable. }\end{array}$ \\
\hline
\end{tabular}




\begin{tabular}{|c|c|c|c|}
\hline & & & $\begin{array}{l}\text { - Variance due to tissue processing/pre-analytical } \\
\text { sample handling. } \\
\text { - Skin quality and biomarker measures can be } \\
\text { influenced by many extrinsic factors, e.g. age, UV } \\
\text { exposure. }\end{array}$ \\
\hline Hair follicles & +++ & $\begin{array}{l}\text { - A source of proliferating epithelial cells that are } \\
\text { useful for the study of many signalling pathways } \\
\text { involved in cancer cell function /anti-cancer drug } \\
\text { mechanism of action. } \\
\text { - Extremely easy to collect from patients and } \\
\text { volunteers. }\end{array}$ & $\begin{array}{l}\text { - Sample processing can be technically challenging and } \\
\text { result in a high degree of sample wastage and loss of } \\
\text { biomarker signal detection. } \\
\text { - Contains very small numbers of cells. Biomarker } \\
\text { expression is typically low and difficult to quantify. } \\
\text { - Requires sensitive and often expensive methods for } \\
\text { marker detection. } \\
\text { - Biomarker expression can vary between follicles } \\
\text { obtained from different locations of the body. }\end{array}$ \\
\hline Urine & +++ & $\begin{array}{l}\text { - Non-invasive. } \\
\text { - Large volumes can be collected. } \\
\text { - Analysis of constituents can indicate } \\
\text { pathophysiology of renal disease. }\end{array}$ & $\begin{array}{l}\text { - High inter- and intra-individual variation. } \\
\text { - Physiological factors such as diet and exercise may } \\
\text { alter biomarker profiles. }\end{array}$ \\
\hline $\begin{array}{l}\text { Cerebrospinal } \\
\text { fluid }\end{array}$ & + & $\begin{array}{l}\text { - Allows directly measurement of PK/PD markers in } \\
\text { the central nervous system (CNS) for CNS } \\
\text { malignancies. }\end{array}$ & $\begin{array}{l}\text { - } \text { Requires specialist clinical expertise for sample } \\
\text { collection. } \\
\text { - } \quad \text { Invasive and potentially risky procedure. } \\
\text { - } \text { Lack of standardised pre-analytical methods leading } \\
\text { to poor reproducibility of data. }\end{array}$ \\
\hline
\end{tabular}




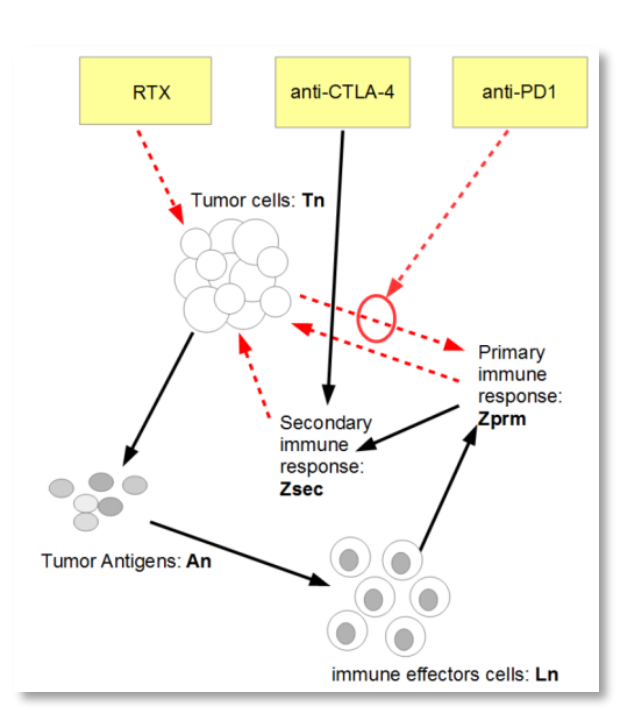

(1)

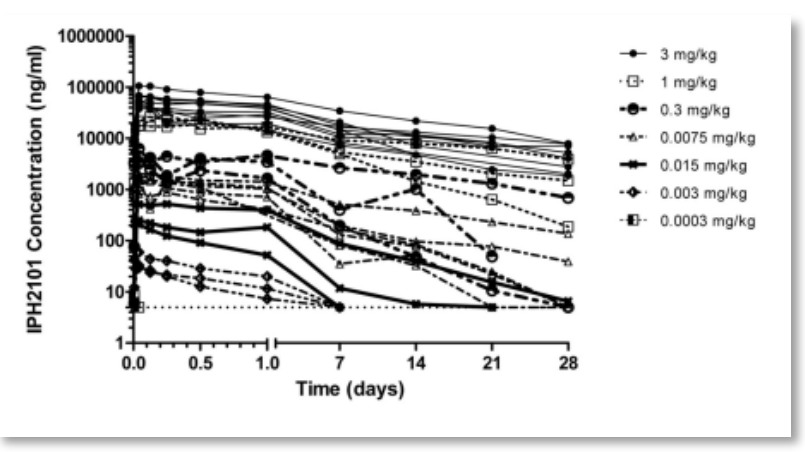

(3)

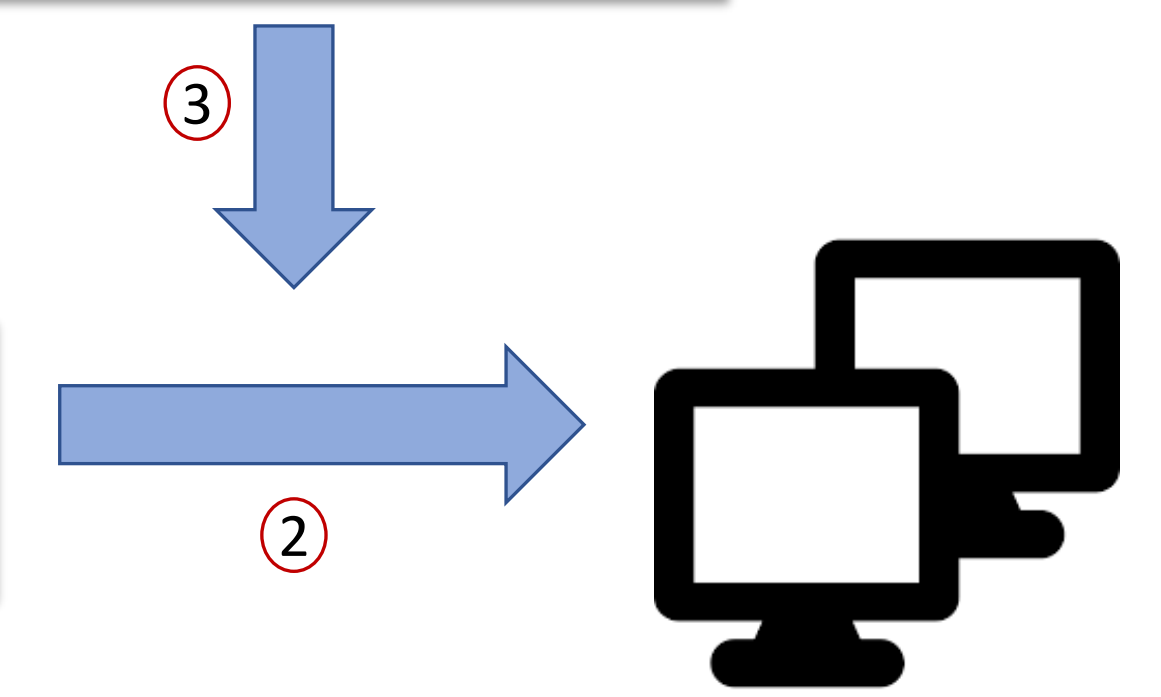

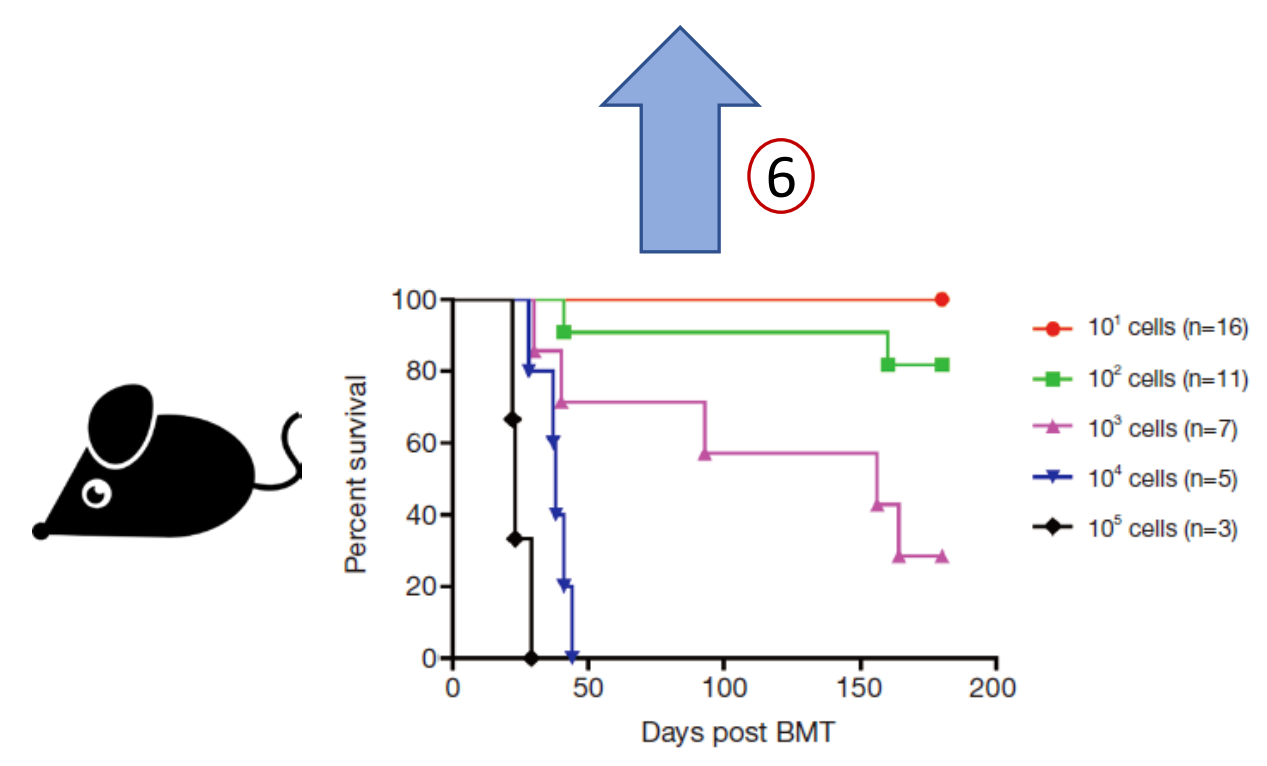

(4)
(5)

$i$

(6)
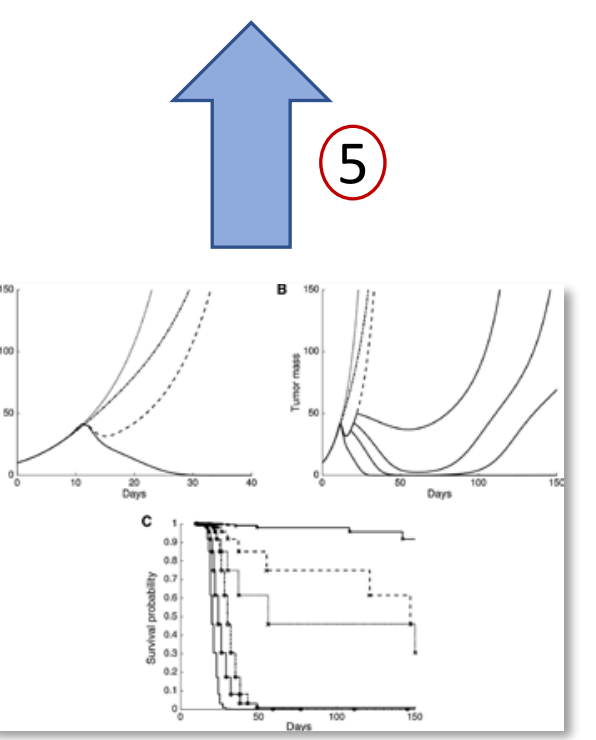


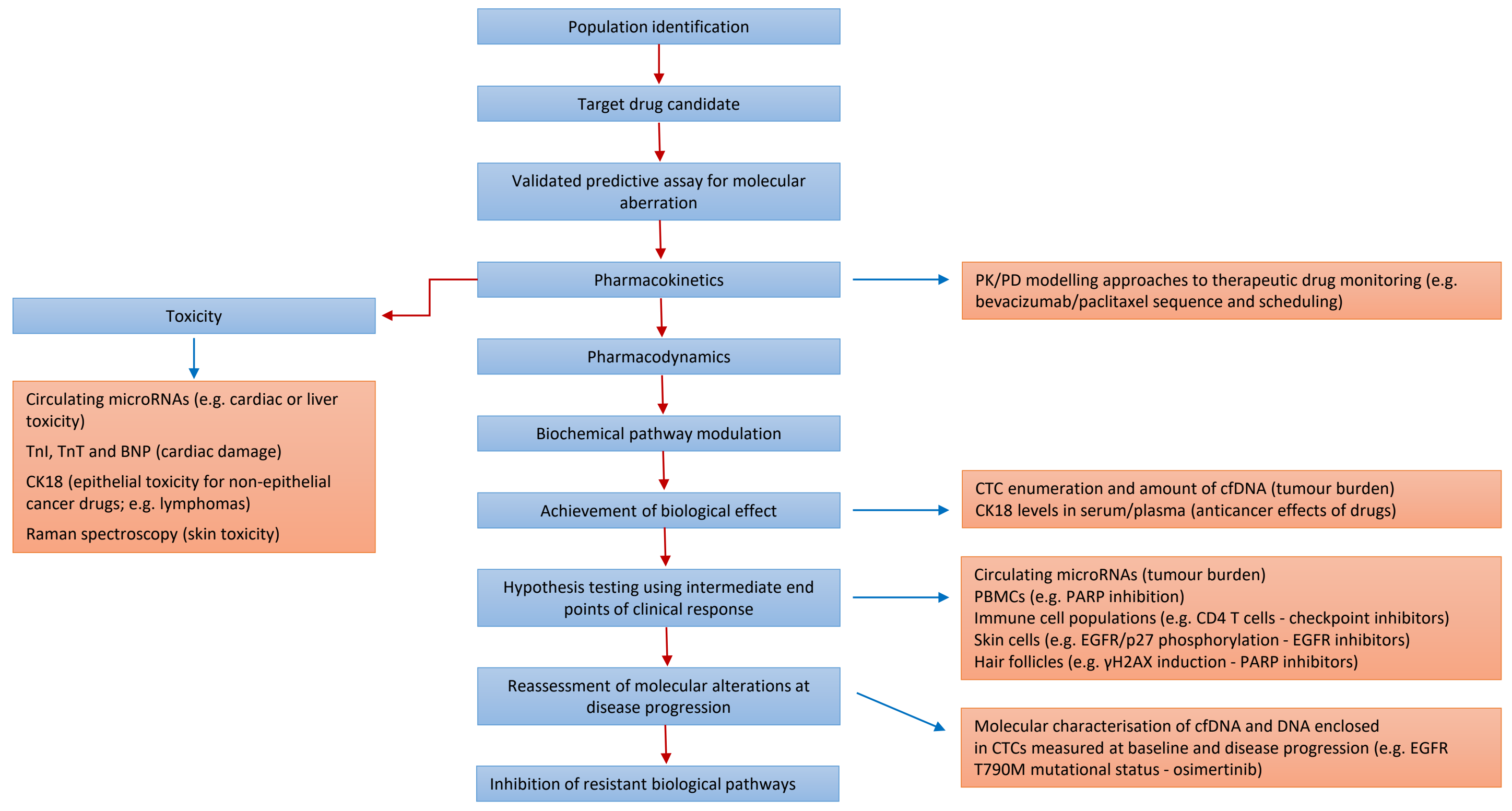

